\title{
EXAMINING COMPONENTS OF DECISION MAKING IN OBSESSIVE-COMPULSIVE DISORDER
}

by

\author{
Jeanine Elizabeth Marcie Lane
}

Bachelor of Health Sciences (Honours), University of Western Ontario, London, Ontario, 2011

Bachelor of Arts (Honours), University of Western Ontario, London, Ontario, 2012

\author{
A thesis \\ presented to Ryerson University \\ in partial fulfillment of the \\ requirements for the degree of \\ Master of Arts \\ in the Program of \\ Psychology
}

Toronto, Ontario, Canada, 2015

(C) Jeanine Lane 2015 


\section{DECISION MAKING IN OCD}

\section{AUTHOR'S DECLARATION FOR ELECTRONIC SUBMISSION OF A THESIS}

I hereby declare that I am the sole author of this thesis. This is a true copy of the thesis, including any required final revisions, as accepted by my examiners.

I authorize Ryerson University to lend this thesis to other institutions or individuals for the purpose of scholarly research.

I further authorize Ryerson University to reproduce this thesis by photocopying or by other means, in total or in part, at the request of other institutions or individuals for the purpose of scholarly research.

I understand that my thesis may be made electronically available to the public. 


\title{
DECISION MAKING IN OCD
}

Examining components of decision making in obsessive-compulsive disorder

\author{
Master of Arts 2015 \\ Jeanine Lane, BHSc., BA. \\ Psychology, Ryerson University
}

\begin{abstract}
The purpose of this study was to examine decision making in individuals with OCD as compared to healthy controls. To the author's knowledge, this was the first study to evaluate decision making in OCD using multiple neuropsychological measures to assess proposed components of the construct, including ambiguity, impulsivity, risk perception, and organizational strategies. It was also believed to be the first study to compare subjective and objective decision making in OCD. Subjective decision making showed poor convergent validity with the three objective measures, as only self-reported indecision was significantly different between groups.

Performance on a memory task, as a proxy for organizational strategies, indicated differences between groups on strategic learning and the effect of interference. Although the presence of decision making deficits remains inconclusive, this study provided support for the conclusion that individuals with OCD have perceived difficulty with decision making, but not necessarily objective deficits. Treatment implications are discussed.
\end{abstract}

Keywords: obsessive-compulsive disorder, decision making, subjective decision making, ambiguity, impulsivity, perception of risk, organizational strategies 


\section{DECISION MAKING IN OCD}

\section{Acknowledgements}

First, I would like to thank my supervisor, Dr. Tisha Ornstein, for her ongoing, gracious support and insight throughout this study. I would also like to extend sincere gratitude to Dr. Kristin Vickers for her enduring assistance and dedication to the study, and to Dr. Martin Antony for agreeing to serve on my examination committee. I am honoured to have worked with such knowledgeable psychologists.

Thank you to Stephanie Taillefer, who was not only a partner on this journey, but also a mentor and friend. I would also like to thank Laurence Lai and Kayla Edwards for all their hard work as research assistants on this project.

Finally, thank you to my fiancé, Robert Sales and my parents, George and Marjorie Lane, for their endless support, patience, guidance, and love. To all my other family members and friends, thank you for making this journey worthwhile. 


\section{DECISION MAKING IN OCD}

\section{Dedication}

This thesis is dedicated to my parents, George and Marjorie Lane, who have taught me so much about life, have spent countless hours helping me with anything and everything, and who have made all of my education and success possible. Your never ending love and unwavering support is an aspiration I hope to fulfill for my own family one day. 


\section{DECISION MAKING IN OCD}

\section{Table of Contents}

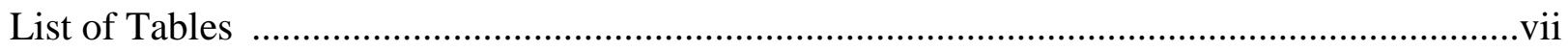

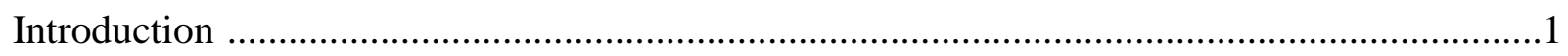

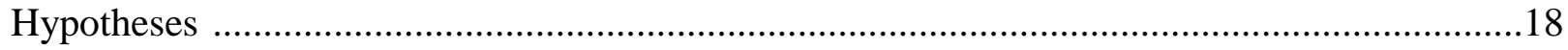

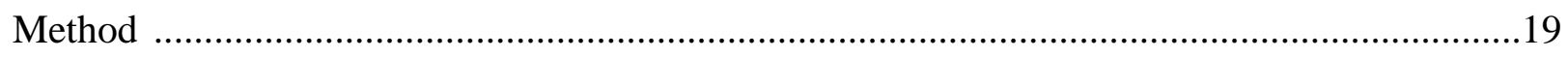

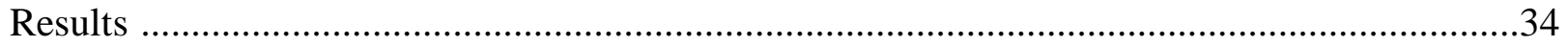

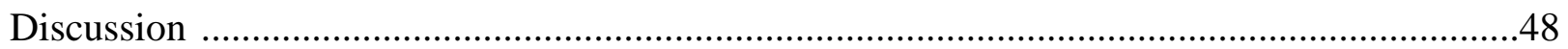

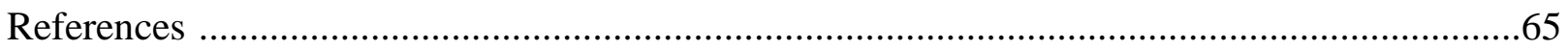




\section{DECISION MAKING IN OCD}

\section{List of Tables}

Table 1: $\quad$ Summary of Studies Examining Decision Making in OCD ................................6

Table 2: $\quad$ Mean Demographic Characteristics Between Groups ........................................35

Table 3: $\quad$ Mean Clinical Information Scores Between Groups ..........................................36

Table 4: $\quad$ Mean Decision Making Performance Between Groups ......................................39

Table 5: $\quad$ Mean Performance on Memory Task Between Groups ......................................40

Table 6: Correlations (r) Among Decision Making Measures .........................................45

Table 7: Other Neuropsychological Measures ............................................................4 


\section{DECISION MAKING IN OCD}

Examining Components of Decision Making in Obsessive-compulsive Disorder Obsessive-compulsive disorder (OCD) is a chronic and disabling condition with a lifetime prevalence of approximately 2.3\% among Canadian adults (Fogel, 2003; Stein, Forde, Anderson, \& Walker, 1997). OCD is characterized by obsessions (unwanted, repetitive and intrusive thoughts, images or impulses that cause marked anxiety or distress) or compulsions (repetitive behaviour or mental acts intended to prevent, reduce or neutralize unbearable anxiety and distress (American Psychiatric Association [APA], 2013). Common obsessions include thoughts about being contaminated by germs or dirt, persistent doubts regarding one's actions or behaviours, the need for symmetry or exactness, and aggressive, sexual and disturbing thoughts or images (APA, 2013; Olley, Malhi, \& Sachdev, 2007; Thobaben, 2012). Associated compulsions often include excessive hand washing and cleaning, repetitive checking behaviours, ordering and arranging, excessive reassurance seeking, and mental acts such as praying and counting, which the person feels driven to perform (APA, 2013; Olley et al., 2007; Thobaben, 2012). Obsessions and compulsions often co-occur in those with OCD (Thobaben, 2012).

The disturbing thoughts and time-consuming behaviours in OCD have a profound negative impact on quality of life, and interfere considerably with academic, occupational and social functioning (APA, 2013). In a study conducted by Sorensen, Kirkeby and Thomsen (2004), 57\% of participants with OCD enrolled in school reported that their symptoms impacted their ability to attend school $(n=70)$, and of those who had a job, $53 \%$ reported an impact on their ability to attend work $(n=115)$. Of the 219 individuals with OCD in the study, $72 \%$ reported that their symptoms affected their social and everyday life functioning, and $27 \%$ indicated that they were dissatisfied with their quality of life (Sorensen et al., 2004). Recent evidence suggests that quality of life may be even poorer in those with comorbid psychological 


\section{DECISION MAKING IN OCD}

disorders (Saleem, Gul, \& Khalily, 2012). OCD is commonly comorbid with sleep difficulties, depression, anxiety disorders, eating disorders, and personality disorders (APA, 2013). Evidence also suggests that individuals with OCD may exhibit deficits in cognitive functioning (Dettore \& O'Connor, 2013; Shin, Lee, Kim \& Kwon, 2014), which likely contributes to the difficulties in day-to-day functioning. Thus, it is not surprising that the World Health Organization (WHO; 2001) reported OCD as one of the ten leading causes of medical disability worldwide.

\section{Theory Underlying the Neurobiology of OCD}

Deficits in cognitive functions, particularly executive control processes (i.e., decision making, response inhibition, cognitive flexibility and planning) have been identified in OCD (Cavedini, Gorini, \& Bellodi, 2006; Olley et al., 2007; Tukel et al., 2012). Evidence from neuroimaging studies supported the involvement of fronto-striato-thalamic circuits, which mediate these cognitive processes (Cavedini et al., 2006; Ping et al., 2013; Menzies, Chamberlain, Laird, Thelen, Sahakian, \& Bullmore, 2008; Whiteside, Port \& Abramowitz, 2004). Specifically, differences in neuronal activity and functional connectivity have been reported in the orbitofrontal cortex in OCD, as compared to healthy controls (Ping et al., 2013; Stern, Welsh, Gonzalez, Fitzgerald, Abelson, \& Taylor, 2013; Whiteside et al., 2004). The orbitofrontal cortex is an important structure for the process of making decisions in terms of evaluating reward and emotion in the context of various outcomes. Evidence from neuropsychological studies has corroborated neuroimaging research in that the orbitofrontal cortex is involved in the pathophysiology of OCD. This was done by demonstrating impaired performance on tests that are known to be sensitive to deficits in the orbitofrontal cortex (Cavedini et al., 2006, Menzies et al., 2008; Shin et al., 2014). Thus, aberrant structural changes appear related to the presentation of cognitive dysfunction. 


\section{DECISION MAKING IN OCD}

\section{Decision Making Defined}

Decision making is defined as the action or process of making decisions, and involves executive functioning and the ability to evaluate environmental information (Dittrich \& Johansen, 2013). Choosing from a set of options is a fundamental part of day-to-day activities. In healthy populations this process occurs over time, while the individual searches for relevant information and then evaluates alternatives in the context of his or her social environment (Raynard, Crozier, \& Svenson, 1997). There is also a postdecision process during which individuals further evaluate their decisions through feedback and the resulting outcome. When examining decision making in clinical populations, it is important to highlight the process of arriving at a decision, rather than the decision itself (Raynard et al., 1997). Overall findings comparing decision making outcomes between individuals with OCD and healthy controls are mixed; therefore, examining the process that leads to outcomes, and the many important variables involved in this process, is important. Examining decision making using various measures can provide insight into these deficits.

\section{Decision Making in OCD}

The literature on OCD is largely focused on deficits in executive functioning more generally, and examining possible endophenotypes (i.e., a term used to describe symptoms of behaviour that may be closer to the underlying pathophysiology of the disorder than the clinical phenomena; Rao, Reddy, Kumar, Kandavel, \& Chandrashekar, 2008). There is little published research on decision making in this population, despite the suggestion that it is a possible endophenotype of OCD (Olley et al., 2007; Vandenbroucke \& Gabriels, 2012). Further identifying the decision-making process may enhance the understanding of the pathophysiology of OCD, given its potential as an endophenotype. Importantly, decision making has been 


\section{DECISION MAKING IN OCD}

reported as a potential predictor of treatment outcomes (Cavedini et al., 2006; Olley et al., 2007; Vandenbroucke \& Gabriels, 2012). A better understanding of decision making in OCD could provide diagnostic information to add to the case conceptualization of individuals with this disorder, and has the potential to enhance the development of more specific and effective treatment interventions. Although some findings have highlighted possible deficits in decision making in OCD (e.g., time required to make a decision may be increased; Dittrich \& Johansen, 2013; Stern et al., 2013), the nature of these deficits remains unclear (Burdick, Robinson, Malhotra, \& Szeszko, 2008; Vandenbroucke \& Gabriels, 2012).

Few studies have explored the neurocognition of decision making in OCD (Cavedini et al., 2006; Dittrich \& Johansen, 2013; Olley et al., 2007). For a summary of these studies, see Table 1. Of those published studies, some demonstrated impairments in decision making in adults with OCD compared to healthy control participants (Cavallaro et al., 2003; Cavedini, Riboldi, D'Annucci, Belotti, Cisima, \& Bellodi, 2002; Da Rocha, Alvarenga, Malloy-Diniz, \& Correa, 2011; Long, Kai, Yi-Fu, Chun-Yan, Ping and Hui-Juan, 2012; Starcke, Tuschen-Caffier, Markowitsch, \& Brand, 2010). Other studies, similarly using the highly popular Iowa Gambling Task (IGT; Bechara, Damasio, Damasio, \& Anderson, 1994) as a measure of decision making, failed to find such differences between OCD and control participants (Dittrich, Johansen, Landro, \& Fineberg, 2011; Lawrence, Wooderson, Mataix-Cols, David, \& Speckens, 2006; Nielen, Veltman, de Jong, Mulder, \& den Boer, 2002).

These mixed results may be due to various factors. For example, inconsistent findings may be due to the fact that the IGT taps multiple components of decision making (Buelow \& Suhr, 2009). Studies to date have largely relied on one or two tasks to examine decision making, and there is also a lack of research examining the process using multimodal methods (e.g., 


\section{DECISION MAKING IN OCD}

subjective and objective measures). Also, differences in sex may be a confounding variable, as males tend to perform better than females on the IGT (Overman et al., 2006). Medication status is another important factor to consider, as those who do not respond to medication tend to exhibit poorer performance on decision-making tasks (Cavedini et al., 2002; Chamberlain, Fineberg, Blackwell, Clark, Robbins, \& Sahakian, 2007).

In addition, severity of symptoms has been suggested as important when examining decision making, as those with more severe symptoms tend to have poorer performance on the IGT (Nielen et al., 2002). Inconsistent results may be due to the clinical heterogeneity of OCD, as previous research has revealed symptom subtypes (e.g., primary symptoms of contamination/cleaning, symmetry/ordering, obsessions/checking and hoarding) and the preliminary association to certain neurocognitive impairments (Leckman et al., 1997; McKay et al., 2004). Importantly, previous research may have included participants with primary hoarding phenomena (with and without obsessive-compulsive symptoms), which is now considered its own diagnostic category in DSM-5 (APA, 2013). Decision making deficits are considered to be a core feature of hoarding (Lawrence et al., 2006; Steketee \& Frost, 2003); thus, poor performance on decision-making tasks in previous studies may be better accounted for by the hoarding disorder rather than OCD. Finally, sample size may be another contributing factor to inconsistent results, as previous studies have varied in their sample sizes. Overall, there is a paucity of published work that has evaluated the various features that encompass the complex process of decision making in OCD, with largely inconsistent results. 


\section{DECISION MAKING IN OCD}

Table 1

Summary of studies examining decision making in $O C D$

\begin{tabular}{|c|c|c|c|c|c|c|c|c|c|c|c|}
\hline \multirow[t]{2}{*}{ Study } & \multirow[t]{2}{*}{ Primary aim } & \multicolumn{2}{|c|}{ Sample size } & \multicolumn{2}{|c|}{ Age, M (SD) } & \multicolumn{2}{|c|}{$\%$ Male } & \multirow[t]{2}{*}{$\begin{array}{l}\text { YBOCS, M } \\
(\mathrm{SD})\end{array}$} & \multirow[t]{2}{*}{$\begin{array}{l}\text { Medication } \\
\text { Status in } \\
\text { OCD }\end{array}$} & \multirow[t]{2}{*}{$\begin{array}{l}\text { Decision- } \\
\text { making } \\
\text { Measures }\end{array}$} & \multirow[t]{2}{*}{ Result } \\
\hline & & OCD & $\mathrm{C}$ & OCD & $\mathrm{C}$ & OCD & $\mathrm{C}$ & & & & \\
\hline $\begin{array}{l}\text { Cavallaro et } \\
\text { al. }(2003)^{1}\end{array}$ & $\begin{array}{l}\text { Examined the } \\
\text { link of } \\
\text { prefrontal cortex } \\
\text { dysfunction to } \\
\text { neuroanatomic } \\
\text { systems in OCD } \\
\text { and } \\
\text { schizophrenia } \\
\text { patients }\end{array}$ & 67 & 56 & $\begin{array}{l}30.50 \\
(8.90)\end{array}$ & $\begin{array}{l}31.20 \\
(6.00)\end{array}$ & 49 & 39 & N/A & $\begin{array}{l}\text { Medication } \\
\text { free for at } \\
\text { least } 2 \\
\text { weeks }\end{array}$ & IGT & $p<.001 * * *$ \\
\hline $\begin{array}{l}\text { Cavendini et } \\
\text { al. }(2002)^{2}\end{array}$ & $\begin{array}{l}\text { Examined OFC } \\
\text { function in OCD } \\
\text { and panic } \\
\text { disorder patients } \\
\text { and whether this } \\
\text { predicted } \\
\text { response to } \\
\text { medication }\end{array}$ & 34 & 34 & $\begin{array}{l}33.70 \\
(11.50)\end{array}$ & $\begin{array}{l}29.50 \\
(8.90)\end{array}$ & 53 & 44 & $\begin{array}{l}28.30 \\
(5.30) \text { and } \\
28.70 \\
(5.90) \text { for } \\
\text { the two } \\
\text { OCD } \\
\text { groups }\end{array}$ & $\begin{array}{l}\text { Medication } \\
\text { free for at } \\
\text { least } 2 \\
\text { weeks }\end{array}$ & IGT & $p=.004 * *$ \\
\hline $\begin{array}{l}\text { Chamberlain, } \\
\text { Fineberg, } \\
\text { Blackwell, et } \\
\text { al. }(2007)^{3}\end{array}$ & $\begin{array}{l}\text { Examined } \\
\text { neurocognitive } \\
\text { functioning in } \\
\text { trichotillomania } \\
\text { and OCD }\end{array}$ & 20 & 20 & $\begin{array}{l}35.30 \\
(14.07)\end{array}$ & $\begin{array}{l}32.15 \\
(7.70)\end{array}$ & $\mathrm{N} / \mathrm{A}$ & $\mathrm{N} / \mathrm{A}$ & $\begin{array}{l}20.40 \\
(4.07)\end{array}$ & $\begin{array}{l}80 \% \text { on } \\
\text { SSRIs }\end{array}$ & $\begin{array}{l}\text { IST } \\
\text { CGT }\end{array}$ & $\begin{array}{l}p=n s \\
p=n s\end{array}$ \\
\hline
\end{tabular}


DECISION MAKING IN OCD

\begin{tabular}{|c|c|c|c|c|c|c|c|c|c|c|c|}
\hline $\begin{array}{l}\text { Chamberlain, } \\
\text { Fineberg, } \\
\text { Menzies, et } \\
\text { al. }(2007)^{4}\end{array}$ & $\begin{array}{l}\text { Examined } \\
\text { genetic } \\
\text { contributions to } \\
\text { inhibitory } \\
\text { control } \\
\text { processes in } \\
\text { OCD patients } \\
\text { and unaffected } \\
\text { relatives }\end{array}$ & 20 & 20 & $\begin{array}{l}32.10 \\
(11.90)\end{array}$ & $\begin{array}{l}33.10 \\
(10.50)\end{array}$ & 20 & 35 & $\begin{array}{l}22.70 \\
(6.60)\end{array}$ & $\begin{array}{l}90 \% \text { on } \\
\text { SSRIs }\end{array}$ & CGT & $p=n s$ \\
\hline $\begin{array}{l}\text { Da Rocha et } \\
\text { al. }(2011)\end{array}$ & $\begin{array}{l}\text { Examined } \\
\text { decision making } \\
\text { in OCD patients }\end{array}$ & 107 & 107 & $\begin{array}{l}28.40 \\
(14.12)\end{array}$ & $\begin{array}{l}29.33 \\
(13.22)\end{array}$ & 54 & 52 & $\begin{array}{l}26.61 \\
(7.70)\end{array}$ & $\begin{array}{l}78 \% \text { on } \\
\text { medication, } \\
52 \% \text { of } \\
\text { those on } \\
\text { SSRIs }\end{array}$ & IGT & $p<.01$ \\
\hline $\begin{array}{l}\text { Dittrich \& } \\
\text { Johansen } \\
(2013)\end{array}$ & $\begin{array}{l}\text { Examined } \\
\text { cognitive } \\
\text { deficits in OCD } \\
\text { patients }\end{array}$ & 13 & 13 & $\begin{array}{l}43.20 \\
(9.50)\end{array}$ & $\begin{array}{l}36.90 \\
(10.20)\end{array}$ & 30 & 39 & $\begin{array}{l}16.20 \\
(6.80)\end{array}$ & $\begin{array}{l}100 \% \text { on } \\
\text { SSRIs }\end{array}$ & CGT & $p=.049^{*}$ \\
\hline $\begin{array}{l}\text { Dittrich et al. } \\
\text { (2011) }\end{array}$ & $\begin{array}{l}\text { Examined risky } \\
\text { and ambiguous } \\
\text { decision making } \\
\text { in OCD by } \\
\text { symptom } \\
\text { dimension }\end{array}$ & 72 & 66 & $\begin{array}{l}41.80 \\
(12.50)\end{array}$ & $\begin{array}{l}37.60 \\
(14.40)\end{array}$ & 39 & 32 & $\begin{array}{l}\text { Ranged } \\
\text { from } 15.80 \\
(3.60) \text { for } \\
\text { sexual/ } \\
\text { religious } \\
\text { symptoms } \\
\text { to } 23.30 \\
\text { (8.20) for } \\
\text { aggressive } \\
\text { symptoms }\end{array}$ & $\begin{array}{l}90 \% \text { on } \\
\text { SSRIs }\end{array}$ & $\begin{array}{l}\text { IGT } \\
\text { CGT }\end{array}$ & $\begin{array}{l}p=n s \\
p=.004 * *- \\
.059 \\
\text { depending on } \\
\text { variable } \\
\text { selected }\end{array}$ \\
\hline
\end{tabular}


DECISION MAKING IN OCD

\begin{tabular}{|c|c|c|c|c|c|c|c|c|c|c|c|}
\hline $\begin{array}{l}\text { Foa et al. } \\
(2003)\end{array}$ & $\begin{array}{l}\text { Examined } \\
\text { amount of } \\
\text { information, } \\
\text { time and risk in } \\
\text { decision making } \\
\text { in OCD patients }\end{array}$ & 18 & 18 & $\begin{array}{l}35.60 \\
(12.10)\end{array}$ & $\begin{array}{l}28.50 \\
(8.90)\end{array}$ & 39 & 44 & $\begin{array}{l}26.77 \\
(5.24)\end{array}$ & N/A & $\begin{array}{l}\text { Decision- } \\
\text { making } \\
\text { scenarios of } \\
\text { low and } \\
\text { high risk }\end{array}$ & $\begin{array}{l}p=n s \text { for } \\
\text { high risk } \\
p<.01^{* *}\end{array}$ \\
\hline $\begin{array}{l}\text { Lawrence et } \\
\text { al. (2006) }\end{array}$ & $\begin{array}{l}\text { Examined OCD } \\
\text { subtypes and } \\
\text { decision making }\end{array}$ & 39 & 40 & $\begin{array}{l}36.10 \\
(11.07)\end{array}$ & $\begin{array}{l}33.48 \\
(10.40)\end{array}$ & 51 & 50 & $\begin{array}{l}25.13 \\
(6.86)\end{array}$ & $\begin{array}{l}77 \% \text { on } \\
\text { medication }\end{array}$ & IGT & $p=n s$ \\
\hline $\begin{array}{l}\text { Long et al. } \\
\text { (2012) }\end{array}$ & $\begin{array}{l}\text { Examined } \\
\text { ambiguity and } \\
\text { risk in OCD } \\
\text { patients }\end{array}$ & 45 & 48 & N/A & N/A & N/A & N/A & N/A & N/A & $\begin{array}{l}\text { IGT } \\
\text { GDT }\end{array}$ & $\begin{array}{l}p=.023^{*} \\
p=n s\end{array}$ \\
\hline $\begin{array}{l}\text { Nielen et al. } \\
(2002)\end{array}$ & $\begin{array}{l}\text { Examined } \\
\text { decision making } \\
\text { in OCD patients }\end{array}$ & 27 & 26 & $\begin{array}{l}34.90 \\
(9.90)\end{array}$ & $\begin{array}{l}31.20 \\
(8.30)\end{array}$ & 26 & 31 & $\begin{array}{l}25.10 \\
(5.20)\end{array}$ & $\begin{array}{l}\text { Medication } \\
\text { free for at } \\
\text { least } 4 \\
\text { weeks }\end{array}$ & IGT & $p=n s$ \\
\hline $\begin{array}{l}\text { Starcke et al. } \\
(2010)\end{array}$ & $\begin{array}{l}\text { Examined } \\
\text { decision making } \\
\text { under ambiguity } \\
\text { and risk in OCD } \\
\text { patients }\end{array}$ & 23 & 22 & $\begin{array}{l}35.25 \\
(7.35)\end{array}$ & $\begin{array}{l}36.50 \\
(10.23)\end{array}$ & 56 & 55 & N/A & $\begin{array}{l}61 \% \text { on } \\
\text { SSRIs } \\
43 \% \text { of } \\
\text { those on } \\
\text { additional } \\
\text { medication }\end{array}$ & $\begin{array}{l}\text { IGT } \\
\text { GDT }\end{array}$ & $\begin{array}{l}p<.001 * * * \\
p=n s\end{array}$ \\
\hline
\end{tabular}




\section{DECISION MAKING IN OCD}

\begin{tabular}{|c|c|c|c|c|c|c|c|c|c|c|c|}
\hline $\begin{array}{l}\text { Stern et al. } \\
(2013)\end{array}$ & $\begin{array}{l}\text { Examined } \\
\text { decision making } \\
\text { and level of } \\
\text { certainty during } \\
\text { fMRI's in OCD } \\
\text { patients }\end{array}$ & 25 & 29 & $\begin{array}{l}25.06 \\
(6.04)\end{array}$ & $\begin{array}{l}27.11 \\
(8.42)\end{array}$ & 48 & 41 & $\begin{array}{l}\text { Medication } \\
\text { free group: } \\
27.70 \\
(4.90) \text {, } \\
\text { Medication } \\
\text { group: } \\
20.10 \\
(4.10)\end{array}$ & $\begin{array}{l}64 \% \\
\text { medicated } \\
\text { with SSRIs }\end{array}$ & $\begin{array}{l}\text { Decision- } \\
\text { making } \\
\text { task } \\
\text { measuring } \\
\text { uncertainty } \\
\text { (see author } \\
\text { for } \\
\text { description) }\end{array}$ & $\begin{array}{l}\text { Decisions } \\
\text { with no } \\
\text { objective } \\
\text { uncertainty: } \\
p<.001 * * * \\
\text { Decisions } \\
\text { with } \\
\text { objective } \\
\text { uncertainty: } \\
p=n s\end{array}$ \\
\hline $\begin{array}{l}\text { Watkins et } \\
\text { al. }(2005)^{5}\end{array}$ & $\begin{array}{l}\text { Examined } \\
\text { cognitive } \\
\text { performance in } \\
\text { Tourette's and } \\
\text { OCD patients }\end{array}$ & 20 & 20 & $\begin{array}{l}38.20 \\
(13.40)\end{array}$ & $\begin{array}{l}36.60 \\
(12.80)\end{array}$ & 40 & 45 & $\begin{array}{l}19.30 \\
(14.30)\end{array}$ & $\begin{array}{l}40 \% \text { on } \\
\text { SSRIs. } \\
10 \% \text { on } \\
\text { other } \\
\text { medication }\end{array}$ & CGT & $p=n s$ \\
\hline
\end{tabular}

Note . $\mathrm{C}=$ Controls; $\mathrm{M}=$ Mean; SD = Standard Deviation; IGT = Iowa Gambling Task; GDT = Game of Dice Task; CGT = Cambridge Gambling Task; IST = Information Sampling Task; YBOCS = Yale-Brown Obsessive-Compulsive Inventory (as a measure of symptom severity); SSRIs = Selective Serotonin Reuptake Inhibitors; OFC = Orbitofrontal cortex; SCRs = Skin Conductance Responses; fMRI = Functional Magnetic

Resonance Imaging; ${ }^{*} p<.05 ; * * p<.01 ; * * * p<.001$, indicating significant differences between OCD and control participants on decision-making measures, with poorer performance in the OCD group than in controls.

Some studies included clinical control groups, which were not described above.

1. Cavallaro et al. (2003): Included 110 schizophrenic patients $(n=233)$.

2. Cavendini et al. (2002): Included 16 panic disorder patients $(n=84)$.

3 . Chamberlain, Fineberg, Blackwell, et al. (2007): Included 20 trichotillomania patients $(n=60)$.

4. Chamberlain, Fineberg, Menzies, et al. (2007): Included 20 first degree relatives of OCD patients $(n=60)$.

5 . Watkins et al., 2005: Included 20 Tourette's Syndrome patients $(n=60)$. 


\section{DECISION MAKING IN OCD}

\section{Components of Decision Making}

Although decision making may be generally thought of as a unitary construct, there are various components of decision making that contribute to this cognitive process. Previous studies appear to have largely focused on ambiguous decision making (i.e., results and probabilities are unknown; Clark, Bechara, Damasio, Aitken, Sahakian, \& Robbins, 2008), with very few studies examining other components of decision making. Examples of other components of decision making include impulsivity, the perception of risk (i.e., uncertain results with known

probabilities; Clark et al., 2008), and organizational strategies (Dittrich \& Johansen, 2013; Foa et al., 2002; Olley et al., 2007; Starcke, Tuschen-Caffier, Markowitsch, \& Brand, 2009; Stern et al., 2013). The limited body of literature supported further investigation of the nature and pattern of decision-making performance in OCD.

Ambiguity. The commonly used IGT is largely studied as a decision-making task that examines ambiguous decision making. However, the construct validity of this measure has been criticized for not clearly identifying which component of decision making the test is attempting to capture (Buelow \& Suhr, 2009). It appears that early on in the task, decisions are based on ambiguous information, whereas later in the task, it measures risky decision making (Brand, Fujiwara, Borsutzky, Kalbe, Kessler, \& Markowitsch, 2005; Brand, Recknor, Grabenhorst, \& Bechara, 2007). However, the point during the task when the concept switches is not clear or identified (Brand et al., 2007). This is problematic as studies that use this task as a measure of ambiguous decision making compare it to tasks that measure risky decision making (Chamberlain, Fineberg, Blackwell, et al., 2007). Dittrich et al., 2011; Long et al., 2012; Starcke et al., 2009; 2010). Further to this, the authors of the measure also claim that performance on the IGT requires the use of organizational strategies (Bechara et al., 1994), another proposed 


\section{DECISION MAKING IN OCD}

component of decision making, yet there are no outcome variables to measure this. Although the current study considered the IGT to measure ambiguous decision making, the poor construct validity should be noted, and likely contributed to the previously inconsistent results. Despite this, the IGT was included in the current study to compare to previous research, as it is a commonly used measure of decision making.

The presence of ambiguity as a component of decision making may be related to intolerance of uncertainty. Intolerance of uncertainty can be defined as a habitual negative reaction to uncertain situations or events (Dugas \& Koerner, 2005). The self-report Intolerance of Uncertainty Scale (IUS; Buhr \& Dugas, 2002) is the most commonly used method to assess this construct. Individuals who are intolerant of uncertainty may exhibit extreme emotional, cognitive or behavioural responses when faced with uncertainty (Buhr \& Dugas, 2002), and thus try to avoid ambiguous situations. Some research has suggested that a high intolerance of uncertainty, in the context of ambiguous situations, underlies difficulties with decision making, as evidenced by compulsive behaviours to gather information to reduce uncertainty (Stern et al., 2013).

Intolerance of uncertainty has been studied in OCD, although to a lesser extent than that seen in other anxiety disorders, such as generalized anxiety disorder (GAD). For example, Gentes and Ruscio (2011) reported that across multiple studies, individuals with OCD reported levels of intolerance of uncertainty similar to those with GAD. Intolerance of uncertainty was also shown to be significantly related to symptom severity among those with specific symptoms of OCD, such as checking (Tolin, Abramowitz, Brigidi, \& Foa, 2003) and hoarding (Oglesby, Medley, Norr, Capron, Korte, \& Schmidt, 2013). Fergus and Wu (2010) reported that intolerance 


\section{DECISION MAKING IN OCD}

of uncertainty was an important cognitive process in OCD, as scores measuring this construct predicted unique variance beyond that of other factors, such as perfectionism.

When making decisions, a greater subjective experience of uncertainty has been reported in OCD as compared to controls (Stern et al., 2013). This study also reported that compared to controls, patients with OCD only had increased difficulty on tasks with subjective uncertainty (i.e., no objective uncertainty inherent in the task) and that there was no differences on tasks that included objective uncertainty (Stern et al., 2013). It is well known that the IGT is a task of ambiguity, and it is possible that scores on this measure, and other measures of decision making, may be related to subjective reports of intolerance of uncertainty.

Impulsivity. It is also suggested that impulsivity is associated with the process of decision making (Bayard, Raffard, \& Gely-Nargeot, 2011). Impulsive behaviours may involve the inability to forgo immediate reward in favour of long term gain, or the inability to use information to predict possible consequences of behaviour (Torregrossa, Quinn, \& Taylor, 2008). In real-life decision making, individuals must consider immediate as well as delayed reward and punishment, all in the context of risk and uncertainty (Bechara et al., 1994). Impulsivity can be measured via self-report questionnaires, such as the Barratt Impulsiveness Scale (BIS-II; Patton, Stanford, \& Barratt, 1995). Using the BIS-II, previous research found that individuals with OCD reported higher impulsivity than controls (Summerfeldt, Hood, Antony, Richter, \& Swinson, 2004; Gupta, Khess, \& Venkatesan, 2013). Previous research also found that high impulsivity resulted in poorer performance on the IGT, as compared to individuals with low impulsivity (Franken, van Strien, Nijs, \& Muris, 2008).

The Information Sampling Task (IST; Clark, Robbins, Ersche, \& Sahakian, 2006) has been previously reported as an objective measure that evaluates impulsivity in relation to 


\section{DECISION MAKING IN OCD}

decision making by evaluating the tendency to gather information before making a decision. The IST has been previously used to examine cognitive flexibility (which is another component of executive functioning) in OCD, and no differences between patients and controls were reported (Fadda, Sottocorno, Martoni, Galimberti, \& Bellodi, 2011). However, it appears that only one study has examined the tendency to gather and evaluate information before making a decision on the IST in OCD (Chamberlain, Fineberg, Blackwell, et al., 2007). This study found a significant difference between individuals with OCD and control participants on the mean number of boxes opened before making a decision in the first condition $(p=.041)$, but this result was no longer significant after corrections for multiples analyses were employed. No differences between groups were found on the same dependent variable in the second condition, even before corrections were made $(p=.090)$. Interestingly, in this study, participants with OCD did not adapt their behaviour between the two conditions $(p=.064)$, but the control group did $(p<.001)$. This result was suggested as indicative of a lack of cognitive flexibility (or cognitive rigidity). The finding suggested possible differences between groups on the task and thus future research is warranted. Given that increased rates of impulsivity are noted in OCD, and that there are limited results on the IST in the literature, increased difficulties on tasks examining impulsivity and decision making in OCD were predicted in the present study.

There are also components of self-reported impulsivity that need to be considered in the context of decision making. These include urgency, which refers to acting impulsively when experiencing negative affect; lack of premeditation, which involves not considering potential outcomes of behaviour; lack of perseverance, which refers to difficulty with continued focus on boring or challenging tasks; and sensation seeking, which refers to openness to new, exciting, potentially dangerous experiences (Bayard et al., 2011; Gupta et al., 2013; Zermatten \& Van der 


\section{DECISION MAKING IN OCD}

Linden, 2008). In healthy undergraduate students, only a lack of premeditation was moderately associated with poorer performance on the IGT (Zermatten, Van der Linden, d'Acremont, Jermann, \& Bechara, 2005). In a more recent follow-up study, higher levels of urgency were associated with poor IGT performance (Billieux, Gay, Rochat, \& Van der Linden, 2010).

There also appeared to be a strong association between symptoms of OCD and impulsive urgency (Zermatten \& Van der Linden, 2008). The foundation of urgency is based on difficulties inhibiting responses. Response inhibition can be measured using tasks such as the Stop-Signal Paradigm (Logan, Cowan, \& Davis, 1984) and the Stroop Color-Word Interference Test (Golden, 1976). Poor inhibition has been related to self-reported impulsivity (Bayard et al., 2011). As summarized by Menzies and colleagues (2008), consistent results indicated deficits in response inhibition in OCD, which provided further evidence that impulsivity may be a factor influencing decision making. Therefore, it is possible that even if impulsivity is low, individuals with OCD may still demonstrate difficulty in decision making due to an inability to inhibit choices based on compulsive symptoms (Zermatten \& Van der Linden, 2008). Differences in the results of studies measuring decision making using the IGT may be related to the influence of impulsivity. Thus, examining the association between impulsivity and decision making is warranted, and inhibition as a factor contributing to differences between OCD and control participants should be examined.

Using the BIS-II, Gupta and colleagues (2013) reported that patients with OCD had higher attention-impulsiveness (similar to a lack of perseverance), and higher nonplanning impulsiveness (similar to a lack of premeditation). These authors concluded that high impulsivity in OCD may be a reason for poor performance on the Cambridge Gambling Task (CGT; Rogers et al., 1999), which is a popular measure of risky decision making (with known probabilities). As 


\section{DECISION MAKING IN OCD}

mentioned, ambiguity and risk perception are also components of decision making. Bayard and colleagues (2011) concluded that decision making under ambiguous situations (as in the IGT) is not likely impacted by impulsivity, but that decision-making performance in situations of risk, is predicted by sensation seeking and urgency. Thus, it appears that further examination of these components is needed.

Risk taking. Research examining the perception of risk in decision making has also compared low and high-risk situations (Foa et al., 2003). This study reported that patients with OCD demonstrated significant differences compared to healthy controls in decision making, but only in low risk situations. For example, OCD patients required more information and more time than controls before making a decision in low risk situations (Foa et al., 2003). Recent studies by Dittrich and Johansen (2013), and Dittrich and colleagues (2011) found significant differences between participants with OCD and controls using the CGT, whereas the majority of other studies found intact decision making in OCD under risky situations (Chamberlain, Fineberg, Blackwell, et al., 2007; Chamberlain, Fineberg, Menzies, et al., 2007; Walkins et al., 2005). Two studies (Long et al., 2012; Starcke et al., 2009) also reported no differences in decision making using the Game of Dice (Brand et al., 2005), which is similar to the CGT in that it measures risky decision making with known probabilities. However, both studies reported significant differences between participants with OCD and controls under ambiguous decision-making situations using the IGT. Another study reported that during risky decision making, high levels of sensation seeking and urgency predicted poorer outcomes on the Game of Dice (Bayard et al., 2011). These studies provide further support that examining decision making using multiple measures to tap different components is important. Although results are inconsistent, it appears 


\section{DECISION MAKING IN OCD}

that decision making under high-risk situations may not be impaired in OCD; however, studies tapping risky decision making, impulsivity, and ambiguity in the same sample are warranted.

Organizational strategies. Following the process of gathering information to make a decision, individuals must apply organizational strategies to evaluate alternatives (Olley et al., 2007). Previous research on executive functioning in OCD consistently highlighted deficits in organizational strategies between OCD patients and healthy controls, using multiple neuropsychological measures (Markarian et al., 2010; Shin et al., 2014). For example, relative to controls, participants with OCD showed significant impairments on the California Verbal Learning Test $2^{\text {nd }}$ Edition (CVLT-II; Delis, Kramer, Kaplan, \& Ober, 2000), which is a test of verbal memory (Shin et al., 2014; Tukel et al., 2012). The CVLT-II taps organizational strategies in the context of strategic learning. Savage and colleagues (2000) reported that organizational strategies mediate performance on memory tasks in OCD. It is therefore possible that deficits in the use of organizational strategies may be implemented in decision making. The CVLT-II also has two outcome variables that directly assess organizational strategies (Delis et al., 2000). Semantic clustering involves the extent to which individuals use the strategy of grouping categorically similar words together, in order to better recall words presented in a list. Alternatively, serial clustering involves the extent to which individuals attempt to recall the words in the same order that they were presented.

According to Bechara and colleagues (1994), the IGT requires the use of organizational strategies during the task, but findings associated with overall performance on the IGT have been inconsistent in the literature thus far, and there are no outcome variables that tap this component of decision making. In addition, there are no decision-making measures designed to assess organizational strategies in the context of decision making. Thus, in the current study, 


\section{DECISION MAKING IN OCD}

performance on the CVLT-II functioned as a proxy measure for this important component of decision making. Although organizational strategies have been indicated as an important part of decision making (Olley et al., 2007), no studies to date have evaluated the relationship of strategic learning deficits and decision making.

In summary, the existing literature evaluating decision making in OCD is largely mixed. This is likely due to various factors, including the fact that multiple components of decision making are rarely considered. The decision-making process has been shown to be negatively affected in individuals with OCD, but more research is needed to determine which components of the process are specifically impaired and under what circumstances (Starcke et al., 2009; Olley et al., 2007). Furthermore, limited published work has examined other possible factors, such as intolerance of uncertainty and impulsivity, which may contribute to the construct of decision making. To the author's knowledge, there are no published studies evaluating decisionmaking performance in the context of all of the aforementioned process components.

\section{Subjective Decision Making}

Indecisiveness is often a prominent clinical symptom for those with OCD (Steketee \& Frost, 2003), yet studies examining subjective reports of decision making are scarce in the literature. The clinical phenomena evidenced in OCD, such as a difficulty discarding items, especially in those with hoarding symptoms (Steketee \& Frost, 2003; Tolin, Kiehl, Worhunsky, Book, \& Maltby, 2008) supports the need to study decision making further. More generally, individuals with OCD have been found to require more information, and need additional time to consider alternative possibilities, before making a decision (Dittrich \& Johansen, 2013; Stern et al., 2013). It is unclear whether decision making deficits are consistent in subjective and objective reporting. To the author's knowledge, subjective and objective decision making have 


\section{DECISION MAKING IN OCD}

yet to be directly compared in OCD. Examining the relationship between subjective and objective decision making would be a novel contribution to the literature on OCD.

\section{Study Goals and Hypotheses}

The primary objective of this study is to explore differences in decision making between individuals with OCD and healthy controls. Further to this, the study aims to elucidate the different components of decision making by determining if there are differences between OCD and control participants across three objective tasks. Based on previous literature, it is hypothesized that: 1) participants with OCD will demonstrate deficits on the IGT as compared to controls; 2) participants with OCD will demonstrate impairments on the IST as compared to controls; and 3) participants with OCD will perform similarly to controls on the CGT. Since organizational strategies appear to be important in decision making, the study aims to examine this component of decision making using a task that taps strategic learning and memory. It is hypothesized that: 4) there will be differences between participants with OCD and controls on strategic learning, as measured by the CVLT-II. The study also aims to determine if there are differences in subjective and objective decision making. It is hypothesized that: 5) subjective decision making based on the FIS will be significantly poorer in participants with OCD compared to controls; and 6) there will be a relationship between subjective decision-making scores and objective measures. Finally, the influence of other psychological factors, including intolerance of uncertainty and components of impulsivity, on decision making will also be examined. It is hypothesized that: 7) there will be a relationship between decision-making outcomes and self-reported intolerance of uncertainty and impulsivity. 


\section{Method}

\section{Participants}

This study included a case-control design comparing participants with diagnosed OCD ( $n$ $=22$ ) and healthy controls $(n=22)$, ages 18 to 65 years. Inclusion criteria for participants with OCD was a principal diagnosis of OCD (minimum symptom duration of 1 year) according to the Structured Clinical Interview for DSM-IV (SCID-IV; First, Spitzer, Gibbon, \& Williams, 1997). Participants in the study were required to endorse symptoms meeting criteria for a principal diagnosis of OCD, which may or may not have included symptoms of hoarding. Exclusion criteria included comorbid bipolar disorder or psychosis, current or recent (within the previous 12 months) substance use disorders, and a history of traumatic brain injury, as identified in the overview section of the SCID-IV. Clinical participants with other comorbid diagnoses, including depression and anxiety disorders, were not excluded from the study, as requiring such would severely limit eligibility and generalizability due to the high rates of comorbidity in this population. However, depression severity is known to hinder cognitive performance (Menzies et al., 2008), which is why individuals with severe depression, as indicated by a score of 29 or greater on the Beck Depression Inventory-II (BDI-II; Beck, Steer, \& Brown, 1996), were excluded. English-speaking control participants with no medical, neurological, or psychiatric conditions were included in the study based on the diagnostic criteria of the SCID-IV.

Recruitment and assessment took place at Ryerson University and the Clinic for OCD and Related Disorders at Sunnybrook Health Sciences Centre. Patients with OCD at the clinic were asked by a research coordinator whether they wished to hear about a research study. If they agreed, they were provided with a description of the study and asked if they would like to participate. A total of $n=19$ participants with OCD were recruited from the hospital. Further 


\section{DECISION MAKING IN OCD}

participants with OCD $(n=3)$, and healthy controls $(n=22)$, were recruited via advertisements at Ryerson University. The study received ethical approval from the Research Ethics Boards at Ryerson University and Sunnybrook Health Sciences Centre. A paid research assistant and a volunteer assisted with the project at the university.

\section{Power}

Between-group differences on various components of decision making and cognitive processes were examined. According to a power analysis, 22 patients with OCD and 22 controls were needed to achieve a moderate effect size $\left(\eta^{2}=.44 ; \alpha=.05 ; 1-\beta=.95\right)$. Power estimates were calculated with G-power calculator using repeated measures analysis of variance (ANOVA), between two groups and across 5 measurements (as there are 5 trials in the IGT). Effect size estimates were calculated based on the results of a study by Da Rocha and colleagues (2011), which compared differences on the IGT between participants with OCD $(n=107)$ and controls $(n=107)$. Due to the limited number of studies comparing decision making between OCD and controls, a conservative approach to power was used estimating sample size based on a $\eta^{2}=.44$, which is larger than the recommended minimum moderate effect size estimate of squared association indices (.25).

\section{Measures}

Participants completed a battery of psychometrically validated tests and questionnaires that included semistructured clinical interviews, self-report questionnaires, paper-and-pencil tasks, and computerized measures.

Clinical measures. OCD symptom severity. Diagnoses and comorbidities were assessed using the SCID-IV (First et al., 1997). The SCID-IV is a highly popular semistructured interview administered by a trained clinician. OCD symptoms and symptom severity were assessed using 


\section{DECISION MAKING IN OCD}

reliable and valid measures of OCD. The Yale-Brown Obsessive-Compulsive Scale (YBOCS; Goodman, Price, \& Rasmussen, 1989) is a semistructured clinical interview administered by a trained clinician. The interview consisted of both a symptom checklist and a severity of symptoms scale, which yielded a total score, and obsessions and compulsions subscale scores. The symptom checklist consisted of a list of common obsessions and compulsions, which were read to the participants with OCD. They then indicated if the symptom was currently present, or was present in the past, and then which of those symptoms were considered principal symptoms that would be targeted in treatment. The list of the principal symptoms was transferred to the severity scale, where participants with OCD rated these symptoms.

The severity scale on the YBOCS inquired about the time spent, interference, distress, resistance, and control of symptoms for both obsessions and compulsions. Each symptom was rated on a 5-point Likert scale from no symptoms (0) to extreme symptoms (4). All items were added for a total score on the YBOCS. Severity of symptoms were scored as follows: $0-7=$ subclinical symptoms; $8-15=$ mild; $16-23=$ moderate; $24-31=$ severe; and $32-40=$ extreme. The YBOCS has been demonstrated to have acceptable to excellent internal consistency $(\alpha=.69$ $.91)$, interrater reliability $(r=.93)$, and test-retest reliability $(r=.61$; Goodman et al., 1989; Woody, Steketee, \& Chambless, 1995). The scale has also shown good convergent validity with other measures of OCD (Woody et al., 1995). The majority of participants with OCD completed the SCID-IV and YBOCS at Sunnybrook Health Sciences Centre, as part of an ongoing genetics study examining OCD and related disorders. Participants with OCD, recruited from the community, completed these interviews as part of the test battery at Ryerson University.

The Obsessive-Compulsive Inventory-Revised (OCI-R; Foa et al., 2002) is an 18-item self-report questionnaire that measures the presence and severity of common OCD symptoms. 


\section{DECISION MAKING IN OCD}

The scale can also be divided into six subscales based on factors measuring dimensions of OCD symptoms, including washing, checking, ordering, obsessing, hoarding, and neutralizing. Each statement was rated on a 5-point Likert scale from not at all disturbed (0) to extremely disturbed (4). Scores range between 0-90, with higher scores indicating greater severity of OCD symptoms. The OCI-R has been shown to have good internal consistency in OCD patients $(\alpha=$ $.83)$, test-retest reliability ( $r=.74-.91)$, convergent validity as indicated by moderate to large correlations with other measures of OCD, and good discriminant validity in distinguishing OCD from other anxiety disorders (Abramowitz \& Deacon, 2006; Foa et al., 2002).

Depression. Depressive symptoms were evaluated using the Beck Depression Inventory$2^{\text {nd }}$ Edition (BDI-II; Beck et al., 1996). The scale is a 21 -item self-report questionnaire that asks individuals to indicate which statement best describes the way they felt in the past 2 weeks. Each statement was rated on a 4-point Likert scale ranging from not at all (0) to extreme (3). Scores range between 0 and 63, with severity of symptoms delineated as follows: 0-13 indicates minimal symptoms, $14-19$ is mild depression, 20-28 is moderate, and 29-63 is severe. The BDIII has been demonstrated to have excellent internal consistency $(\alpha=.92)$, and test-retest reliability $(r=.93)$. Convergent validity was also shown, as indicated by moderate to large correlations with other measures of depression, such as the Hamilton Depression Rating Scale, at pretreatment $(r=.30)$ and posttreatment $(r=.81$; Beck et al.,1996; Schneibel, Brakemeier, Wilbertz, Dykierek, Zobel, \& Schramm, 2012).

Anxiety. Symptoms of anxiety were assessed using the Beck Anxiety Inventory (BAI; Beck, Epstein, Brown, \& Steer, 1988), which primarily measures physical symptoms of anxiety. The scale is a 21-item self-report questionnaire in which individuals rate the extent to which the statement applies to them (Beck \& Steer, 1993). Each statement is rated on a 4-point Likert scale 


\section{DECISION MAKING IN OCD}

ranging from not at all (0) to severely (3). Scores range between 0-63, and were interpreted as follows: 0-7 indicates minimal or normal level of anxiety, 8-15 is mild anxiety, 16-25 is

moderate, and 26-63 is severe. The BAI has been shown to have excellent internal consistency ( $\alpha$ $=.92)$, and good test-retest reliability $(r=.75)$. Convergent validity was also demonstrated as indicated by moderate to large correlations with other measures of anxiety, such as the Hamilton Anxiety Rating Scale-Revised $(r=.51)$, and both the state $(r=.47)$ and trait $(r=.58)$ subscales on the State-Trait Anxiety Inventory (STAI; Beck et al.,1988; Beck \& Steer, 1993).

Quality of Life. The Quality of Life Enjoyment and Satisfaction Questionnaire-Short Form (QLES; Stevanovic, 2011) is a 16-item self-report questionnaire, that measures the extent to which an individual is satisfied with their life and current circumstances based on physical health, mood, work, activities, relationships, functioning, sexual desire, economic status, overall well-being, and medication. Each statement was rated on a 5-point Likert scale ranging from very poor (1) to very good (5) in the past week. Scores range between 16-70 (as the item for medication status may be not applicable and is thus rated separately, and the item regarding overall well-being is rated separately), with higher scores indicating better quality of life. The QLES has demonstrated excellent internal consistency $(\alpha=.90)$, and test-retest reliability $(r=$ .93), as well as convergent validity with related measures assessing quality of life (Stevanovic, 2011).

Objective decision making measures. Three objective neuropsychological tests of decision making were included in the battery of tests. These included the IGT (Bechara et al., 1994), the IST (Clark et al., 2006), and the CGT (Rogers et al., 1999).

Ambiguity in decision making. The IGT is a well-known neuropsychological measure of decision making. The task tests the ability to forgo immediate reward for long-term gain, under 


\section{DECISION MAKING IN OCD}

ambiguous situations (i.e., with no known probabilities). This measure was designed to mimic real-life decision making, due to the uncertainty involved in the choices, as results and probabilities are unknown or cannot be precisely calculated (Bechara et al., 1994). Participants were asked to select a card from one of four possible decks (A, B, C, D) for 100 trials, which was divided in 5 blocks. They were told that they can select cards from the decks in any order. Each time they selected a card, they either received money ( $\$ 100$ for decks $A$ and $B$, and $\$ 50$ for decks C and D), or had to pay money. There were random reward and punishment schedules for each deck, that the participant is initially unaware of, as they were only told that some decks are "worse" than others. Decks A and B were considered disadvantageous decks as they resulted in large immediate cash rewards, but had larger losses over time. Decks C and D were considered advantageous desks as they resulted in smaller more consistent immediate cash rewards, with fewer losses. The IGT net score was calculated by the number of cards selected from the advantageous decks minus the number of cards selected from the disadvantageous decks $[(\mathrm{C}+\mathrm{D})$ $(\mathrm{A}+\mathrm{B})]$. The test measured learning over time, where participants should gradually choose less cards from A and B and more cards from C and D. A higher score indicated better performance on the task, as it meant the participant was choosing more cards from the advantageous decks. The participants were asked to try and earn as much money as possible, or to simply avoid losing money. Impaired performance on this task has been shown to be sensitive to patients with orbitrofrontal cortex damage (Cavedini et al., 2002).

Impulsivity in decision making. The IST is a computerized measure, part of the Cambridge Neuropsychological Test Automated Battery (CANTAB; Cambridge Cognition Ltd, 2006). This task assessed decision making and impulsivity by examining the tendency to gather and evaluate information before a decision was made. The test was also designed to measure 


\section{DECISION MAKING IN OCD}

cognitive flexibility, which was not examined in this study. The IST took about 12 minutes to complete. Participants started by seeing a grid of 25 grey boxes on the screen. Participants were required to decide which colour was more prevalent (e.g., yellow or blue) hidden under the grey boxes. By touching the grey boxes, the colours were revealed. In the first condition (referred to as the no cost condition), participants were instructed that they could open as many boxes as they wish before deciding which colour there was more of. To make a decision, they simply touched the coloured panel at the bottom of the screen. For each correct decision, participants were awarded 100 points. In the second condition (the cost condition), as the number of boxes opened increased, the amount of points won decreased. Participants were told that on these trials, the amount you can win starts at 250 points, and decreases by 10 points for every box that is touched. In both conditions, there were 10 trials, and there was a 100-point penalty for wrong decisions.

Six dependent variables on the IST were included in the study (three variables, each calculated for both the cost and no cost conditions). The mean number of boxes opened per trial is the most commonly reported dependent variable on this test. It was expected that in the no cost condition, more boxes would be opened than in the cost condition. A greater number of boxes opened indicated the need to gather more information before making a decision, out of a total of 25 boxes. The number of sampling errors indicated the number of incorrect decisions made, which was measured in each condition. It was expected that more errors would be made in the cost condition than the no cost condition. A greater number of errors indicated more impulsiveness in making decisions. Finally, the total number of trials correct was a measure of overall performance on the test. A greater number of trials correct indicated better performance on the test, out of a total of 10 trials per condition. 


\section{DECISION MAKING IN OCD}

Risky decision making. The CGT is a computerized measure, part of the CANTAB (Cambridge Cognition Ltd, 2006). This task was also employed to measure risk-taking behaviour in decision making, based on the perception of risk with known probabilities. The CGT took about 25 minutes to complete. On each trial, the participant was presented with 10 boxes, with a varying proportion of red and blue boxes. Participants were instructed that the computer had hidden a yellow token behind one of the boxes. They were expected to indicate which coloured box (blue or red) they believed the token was hidden under, and then wager a desired number of points to bet on the answer. The ratio of blue to red boxes changed randomly and participants were expected to use probabilities to guess the answer. In the first set of 36 trials, the number of points to bet was shown on the screen in ascending order, so participants could choose the size of their bet by touching the screen. In the second set of 36 trials, points were presented in descending order, starting with the highest possible bet. After each response, participants were told whether they are right or wrong, and the points were added or subtracted from the total score. An individual with greater impulsivity was expected to choose low bets in the ascending condition and high bets in the descending condition, whereas someone with high risk taking behaviour would likely wait for the bets to increase in the ascending condition, but would quickly select bets in the descending condition.

Four dependent variables on the CGT were included in the study. The probability of rational decisions, measured the overall proportion of the bet placed, in relation to the probability that the colour selected was correct. A lower score on this variable indicated greater self-control. Deliberation time was the mean time elapsed in seconds between when the coloured boxes were presented and when the choice was selected, which measured a component of impulsivity. Lower scores indicated greater impulsiveness in responses. The probability of quality decisions 


\section{DECISION MAKING IN OCD}

measured the proportion of trials that the more likely outcome was chosen (i.e., the colour with the greater probability). A higher score indicated better performance. Finally, the probability of risk taking measured the mean proportion of the total points gambled. Lower scores indicated greater self-control.

Strategic learning. As there are no decision-making tasks (or outcome variables on these tasks) that tap organizational strategies, a memory measure was included in the study to examine organizational strategies. The CVLT-II (Delis et al., 2000) measures verbal memory by having participants recall words presented in a list. The assessor began by reading a list of 16 words to participants. Participants were then asked to recall as many words as they could from memory, which was repeated for 5 trials. The list contained an imbedded semantic structure, consisting of four different categories of words (vegetables, ways of travelling, furniture, and animals). The words were presented in a random order (where two words from the same category were never in sequential order), and participants were not primed to notice this semantic structure. Next, a second list of 16 words was presented with another four categories, and participants were instructed to recall words from the second list for one trial. This trial acted as interference, as participants were then asked to again recall words from the first list, which was read several times (considered a short delay). After a 20-minute delay (long delay), participants were asked to recall words from the first list, and then were subsequently primed to recall words from each of the four semantic categories. Finally, after a 10-minute delay, a recognition test was presented, where participants were instructed to identify which words were presented in the first list. The greater number of words recalled in each trial, the better the verbal memory performance.

Performance on the CVLT-II improves when organizational strategies are implemented during the learning trials when participants are presented the same 16 words, five times. A 


\section{DECISION MAKING IN OCD}

dependent variable included in this study was a score of retroactive interference, which examined the extent to which the presentation of a second word list interfered with recall of words from the first list during the short delay. Although this measure taps memory performance, the focus in the current study was on the two outcomes variables that assessed organizational strategies: semantic and serial clustering. A semantic clustering score measured the degree to which participants grouped words from the same category together in order to facilitate recall. The more words from the same category that were recalled in order, the better the score. A serial clustering score measured the degree to which participants attempted to recall words in the same order as initially presented. The more words recalled in sequential order, the better the score. All outcomes were calculated and scored using the CVLT-II computerized scoring software, which accounted for age, sex, education and ethnicity.

Subjective decision making. The Frost Indecisiveness Scale (FIS; Frost \& Shows, 1993), is a 15-item self-report questionnaire that measures perceived everyday decision making. Each statement was rated on a 5-point Likert scale ranging from strongly disagree (1) to strongly agree (5). Six items were reverse coded (Questions 2, 3, 5, 6, 8, and 9). Scores range between 15 and 75 , with higher scores indicating greater difficulty with decision making or indecisiveness. The scale has been shown to have excellent internal reliability $(\alpha=.90$; Frost $\&$ Shows, 1993).

Other psychological measures. In order to further examine components of decision making, two related self-report questionnaires were included in the study. The purpose of these measures was to measure intolerance of uncertainty and impulsivity.

Intolerance of Uncertainty. The Intolerance of Uncertainty Scale (IUS; Buhr \& Dugas, 2002) is a 27-item self-report questionnaire that measures differing levels of negative beliefs and reactions to uncertainty, ambiguous situations, and beliefs about the future. Each statement was 


\section{DECISION MAKING IN OCD}

rated on a 5-point Likert scale from not at all characteristic of me (1) to entirely characteristic of me (5). Scores range between 27 and 135, with higher scores indicating greater intolerance of uncertainty. The IUS exhibited excellent internal consistency $(\alpha=.94)$, good test-retest reliability $(r=.74)$, and convergent validity with related cognitive constructs, including worry, neuroticism, and anxiety (Buhr \& Dugas, 2002; McEvoy \& Mahoney, 2011).

Impulsivity. The Barratt Impulsiveness Scale-II (BIS-II; Patton et al., 1995) is a 30-item self-report questionnaire that measures the behavioural construct/personality trait of impulsivity. The scale was broken down into higher order factors (attentional impulsivity, motor impulsivity and nonplanning impulsivity). These factors can be further isolated into lower order factors: attentional impulsivity is composed of attention and cognitive instability subscales; motor impulsivity is composed of motor and perseverance subscales; and nonplanning impulsivity is composed of self-control and cognitive complexity. Each statement was rated on a 4-point Likert scale ranging from rarely/never (1) to almost always/always (4). Ten items were reverse coded (Questions 1, 7, 8, 9, 10, 12, 13, 15, 20 and 29). Scores range between 30 and 120, with higher scores indicating greater impulsivity. The scale has been shown to have good internal consistency on the total scale $(\alpha=.83)$, and on the attentional $(\alpha=.74)$, and nonplanning $(\alpha=$ .72), subscales (Stanford, Mathias, Dougherty, Lake, Anderson, \& Patton, 2009). However, the motor subscale demonstrated poor internal consistency $(\alpha=.59)$. The BIS-II has also shown high concurrent validity with other commonly used measures of impulsivity (Stanford et al., 2009).

Other cognitive measures. An intelligence measure was included to determine premorbid functioning and to acquire a baseline level of functioning. In addition, in order to better say that any performance decrements found among OCD patients were not the result of slowed motor speed or thinking speed, or an inability to inhibit a response, measures of 


\section{DECISION MAKING IN OCD}

psychomotor speed, information processing speed, and inhibition of motor and cognitive responses were also employed.

The Wechsler Test of Adult Reading (Holdnack, 2001) is a proxy measure for premorbid functioning, assessed by examining reading ability. Participants were asked to read a list of words out loud, and were given a score of 1 if the word was pronounced correctly or 0 if it was pronounced incorrectly. The words on the list progressively became more difficult over time. There were 50 words in total and thus scores range between 0-50, with higher scores indicating higher reading ability.

The Finger Tapping Test (Heaton, Grant, \& Matthews, 1992) is a measure of psychomotor speed. Participants tapped their index finger on a lever as rapidly as possible for 10 seconds. The number of taps was recorded for each trial, with a greater number of taps indicating greater speed. The task was repeated until 5 consecutive trials were within 5 points of each other, up to a maximum of 10 trials. The dependent variables were the mean scores of the combined trials for both the dominant and nondominant hands.

Digit Symbol-Coding (Wechsler, 1997) is a measure of cognitive processing speed, and is part of the Wechsler Adult Intelligence Scale-III. This task was completed on a sheet of paper using a pencil. Across the top of the page there were numbers associated with corresponding symptoms (e.g., 1= O, 2=>). On the rest of page, there were boxes with numbers in a random order printed in the upper portion, and blank spaces in the lower portion. Participants were instructed to copy the corresponding symbol in the boxes below the numbers. They were further instructed to complete the boxes in order, without skipping any, and to work as fast as possible. The dependent outcome was the number of correct symbols copied in 2 minutes, with a greater 


\section{DECISION MAKING IN OCD}

number of items completed indicating better performance. Incorrectly drawn symbols were subtracted from the total score.

The Stop-Signal Paradigm (Logan, Cowan, \& Davis, 1984) tested the speed for executing and voluntarily inhibiting a motor response. Participants were asked to watch a computer screen that presented a fixation point in the middle of the screen. Participants were asked to press corresponding buttons in response to " $\mathrm{X}$ "s and "O"s sequentially presented in the middle of the screen, as quickly as they could. The stop signal is an audible tone that occurred at random intervals between the presentation of letters. Participants were asked to inhibit their response of pressing the corresponding button when they heard the tone. The primary dependent variable was the stop signal reaction time (SSRT), measured in seconds, where a shorter time indicated better performance. This outcome measures the latency between the presentation of the sound, and the initiation of inhibiting the response, which is calculated by subtracting the mean delay from the mean reaction time.

The Stroop Color-Word Interference Test (Golden, 1976) evaluated cognitive response inhibition across 3 trials. The first trial (word trial) required participants to read a list of words (colours) as fast as they could in 45 seconds. The second trial required that they read the colour of the ink that a series of "XXX"s were printed in (colour trial). The final trial required participants to read the colour of the ink that the word was in, inhibiting the response to read the word itself (word/colour interference). On this trial, there was a discrepancy between the word (e.g., blue) and the colour of the ink (e.g., red). The scores for each trial were based on the number of words read, where a greater number of words indicated better performance. 


\section{DECISION MAKING IN OCD}

\section{Procedure}

Once recruited, participants were provided with a description of the study, including purpose, length of time, risks, etc. Participants completed a phone screen interview conducted by a research assistant to determine eligibility. Questions were related to background information and symptoms of psychological disorders. Individuals for whom inclusion criteria were met were invited to participate and those for whom inclusion criteria were not met were told the reason for their exclusion (e.g., that the tests required colour vision and English fluency). Participants were also required to provide informed consent to participate in the study.

Testing was conducted by two trained graduate students at the Master's and Doctoral levels in Clinical Psychology. Each assessment took place over the course of one session of approximately 4 hours, with offered breaks between measures, as required. The two interviews (SCID, YBOCS) were completed first. In order to avoid interference effects, tests measuring similar modalities (e.g., verbally mediated tests) were not placed in sequential order of administration. All participants received a fixed administration order and participants were compensated $\$ 25$ for their time.

\section{Data Analysis}

The data were analyzed using the Statistical Package for Social Sciences, Version 21 (SPSS). Analyses consisted of a comparison of demographic information between participants with OCD and controls using independent samples $t$-tests and chi-square analyses. Independent samples $t$-tests were also conducted to determine if there were significant differences between OCD and control participants on measures of decision making, psychological measures, and neuropsychological measures. Between-group (OCD, control) differences on tasks where there were several levels of difficulty were analyzed using mixed ANOVA. To ascertain if there were 


\section{DECISION MAKING IN OCD}

relationships among the decision-making variables and psychological measures, Pearson's correlation coefficients were computed. Further analyses included regression and moderator

analyses to examine the relationship between decision making, intolerance of uncertainty and impulsivity.

All assumptions of parametric tests were met, including normality, independent groups, interval level data, and homogeneity of variance, with a few exemptions. In the instances where an assumption had been violated, this was reported within the Results section. Participants were excluded pair-wise from analyses for missing data points, which reduced the sample size for that test. However, these participants were still included in the analyses for the tests for which they had complete data. As the statistical tests completed were designed to examine neuropsychological performance based on a priori hypotheses, each measure was viewed as a separate analysis for statistical purposes (Lawrence et al., 2006). Thus, significant results were based on a $p$ value of $<.05$ and all tests were two-tailed.

There is high comorbidity between OCD and depression, and depression is well known to have an impact on cognitive performance (Menzies et al., 2008). Thus, it is possible that depression may impact decision-making ability among those with OCD. To examine if OCD diagnostic status maintained significance in terms of predicting performance when depression scores were taking into account, hierarchical regression analyses were conducted. 


\section{Results}

\section{Demographics}

Demographic characteristics for participants with OCD $(n=22)$ and healthy controls $(n=$ 22) are shown in Table 2. Independent samples $t$-tests were conducted to compare groups on age, level of education, and premorbid functioning. The OCD and control groups did not differ in age, $t(42)=-.86, p=.398$, or years of education, $t(42)=-.72, p=.476$. There were no significant differences between groups on the WTAR, which is a measure of premorbid function, $t(42)=-$ $1.99, p=.053$, indicating that both groups had comparable reading ability. To compare sex and ethnicity between groups, Pearson's chi-square tests were conducted. The two groups also did not differ for sex, $\chi^{2}(1)=1.47, p=.226$. The assumption of expected frequencies was not met for ethnicity, indicating the need to collapse across the groups. The majority of the sample identified as Caucasian (59\%), and therefore the groups were collapsed into Caucasian and other. There was a significant association between group status (OCD, control) and ethnicity, $\chi^{2}(1)=$ $6.02, p=.031, \varphi=-.370$. participants with OCD were 1.89 times more likely to be Caucasian than healthy controls, and thus the influence of ethnicity on outcomes was considered in subsequent analyses.

\section{Clinical Information}

Clinical information, including scores on measures assessing severity of anxiety and depression are presented in Table 3. According to the SCID-IV, all clinical participants had a principal diagnosis of OCD. The majority of the sample also had comorbid diagnoses, including major depressive disorder/dysthymic disorder (23\%), trichotillomania/impulse control disorder not otherwise specified (18\%), hoarding (based on an insert of questions added to the SCID-IV; $14 \%$ ), and other anxiety disorders, including specific phobia (14\%), panic disorder (1\%), social 


\section{DECISION MAKING IN OCD}

anxiety disorder (1\%) and generalized anxiety disorder (1\%). No psychological diagnoses were present in the control group. The mean YBOCS score in the OCD group indicated a moderate severity of symptoms $(M=22.41, \mathrm{SD}=7.04)$. As expected, there were significant differences between groups for severity of OCD symptoms. On the OCI-R, participants with OCD $(\mathrm{M}=$ 26.27, $\mathrm{SD}=9.71)$ reported greater symptoms than controls $(\mathrm{M}=7.27, \mathrm{SD}=7.69), t(42)=-7.20$, $p<.001$. As expected, few OCD symptoms were reported by healthy controls.

Table 2

Mean Demographic Characteristics Between Groups

\begin{tabular}{|c|c|c|c|c|c|}
\hline Characteristic & $\begin{array}{l}\mathrm{OCD}(n=22) \\
\mathrm{M}(\mathrm{SD})\end{array}$ & $\begin{array}{l}\text { Control }(n=22) \\
\mathrm{M}(\mathrm{SD})\end{array}$ & Statistic & $p$ & $\begin{array}{l}\text { Effect } \\
\text { Size }\end{array}$ \\
\hline Age (years) & $\begin{array}{l}37.23(13.53) \\
(\text { range }=21-65)\end{array}$ & $\begin{array}{l}33.50(15.34) \\
(\text { range }=19-64)\end{array}$ & $t(42)=-0.86$ & .398 & $r=.13$ \\
\hline Females: Male & $12: 10$ & $8: 14$ & $\chi^{2}(1)=1.47$ & .364 & $\varphi=.18$ \\
\hline Education (years) & $16.39(2.60)$ & $15.89(1.96)$ & $t(42)=-0.72$ & .476 & $r=.11$ \\
\hline Ethnicity & & & $\chi^{2}(1)=6.02$ & $.031 *$ & $\varphi=-.37$ \\
\hline Caucasian (\%) & 77 & 41 & & & \\
\hline Asian $(\%)$ & 9 & 41 & & & \\
\hline African American (\%) & 0 & 9 & & & \\
\hline Hispanic/Latino (\%) & 5 & 5 & & & \\
\hline Native American (\%) & 5 & 0 & & & \\
\hline Other $(\%)$ & 5 & 5 & & & \\
\hline WTAR & $44.82(3.45)$ & $41.86(6.06)$ & $t(42)=-1.99$ & .053 & $r=.29$ \\
\hline
\end{tabular}

There were also differences between groups on other measures of psychopathology. On the measures of anxiety and depression, Levene's tests, BAI: $F(1,41)=5.85, p=.020$, BDI-II: $F(1,41)=5.43, p=.025$, were significant, indicating that the assumption of homogeneity of variances was not met. Therefore, an analysis that did not assume homogeneity of variance was adopted, which revealed a significant group effect on the BAI, $t(32.63)=-4.49, p<.001$, and BDI-II, $t(35.77)=-5.01, p<.001$. The range of anxiety scores for participants with OCD was 0 to 33. As a group, participants with $\mathrm{OCD}(\mathrm{M}=15.52, \mathrm{SD}=9.82)$ reported a mild anxiety 


\section{DECISION MAKING IN OCD}

symptom presentation, whereas controls reported minimal symptoms $(\mathrm{M}=4.36, \mathrm{SD}=5.94)$. The range of depression scores for participants with OCD was 0 to 28. As a group, participants with OCD $(\mathrm{M}=17.18, \mathrm{SD}=9.18)$ also reported mild symptoms of depression, whereas controls reported minimal symptoms $(\mathrm{M}=5.48, \mathrm{SD}=5.83)$. To examine self-reported quality of life, the difference between groups on the QLES was examined. As expected, results indicated that participants with $\mathrm{OCD}(\mathrm{M}=44.63, \mathrm{SD}=9.47)$ reported poorer quality of life than controls $(\mathrm{M}=$ $52.63, \mathrm{SD}=8.88), t(42)=2.47, p=.020$.

Table 3

Mean Clinical Information Scores Between Groups

\begin{tabular}{|c|c|c|c|c|c|}
\hline Measure & $\begin{array}{l}\mathrm{OCD}(n=22) \\
\mathrm{M}(\mathrm{SD})\end{array}$ & $\begin{array}{l}\text { Control }(n= \\
\mathrm{M}(\mathrm{SD})\end{array}$ & Statistic & $p$ & $\begin{array}{l}\text { Effect } \\
\text { Size }(r)\end{array}$ \\
\hline Age of Onset & $17.75(13.12)$ & N/A & & & \\
\hline OCI-R & $26.27(9.71)$ & 7.27(7.69) & $t(42)=-7.20$ & $<.001 * * *$ & .74 \\
\hline YBOCS total & $22.41(7.04)$ & N/A & & & \\
\hline YBOCS-O & $11.64(3.57)$ & N/A & & & \\
\hline YBOCS-C & $10.68(4.55)$ & N/A & & & \\
\hline BDI-II & $17.18(9.18)$ & $5.48(5.83)$ & $t(35.77)=-5.01$ & $<.001 * * *$ & .64 \\
\hline BAI & $15.52(9.82)$ & $4.36(5.94)$ & $t(32.63)=-4.49$ & $<.001 * * *$ & .62 \\
\hline QLES & $44.63(9.47)$ & $52.63(8.88)$ & $t(42)=2.47$ & $.020 *$ & .36 \\
\hline
\end{tabular}

Note. $\mathrm{M}=$ Mean; $\mathrm{SD}=$ Standard deviation; OCI-R = Obsessive-Compulsive Inventory-Revised; YBOCS = Yale-Brown Obsessive-Compulsive Scale; YBOCS-O = Yale-Brown ObsessiveCompulsive Scale Obsessions subscale; YBOCS-C = Yale-Brown Obsessive-Compulsive Scale Compulsions subscale; BDI-II = Beck Depression Inventory-II; BAI = Beck Anxiety Inventory; QLES = Quality of Life and Enjoyment Survey; ${ }^{*} p<.05 ; * * p<.01$; *** $p<.001$. Levene's test was significant $(p<.05)$ for the BDI-II and BAI, thus equal variances were not assumed.

In total, $59 \%$ of participants in the OCD group were on psychotropic medication. Of those participants, $36 \%$ were on selective serotonin reuptake inhibitors (SSRIs), including sertraline, escitalopram, paroxetine, and fluoxetine. Of those taking SSRIs, four participants were 


\section{DECISION MAKING IN OCD}

taking additional medications (one was also on an investigational new drug, one was on cyclohexan, one was on buproprion, and one was on mirtazapine and risperidone). Of those participants on medication, $14 \%$ were on selective norepinephrine reuptake inhibitors (SNRIs), including venlafaxine and duloxetine. Of those taking SNRIs, one participant was also taking buproprion and lisdexamfetamin dimesylate. An additional $9 \%$ of participants were taking benzodiazepines, including clonazepam (this participant was also on aripiprazole) and alprazolam. Finally, an additional participant (5\%) was on an unknown medication. Only one control participant was on a psychotropic medication (alprazolam), which was being prescribed as a muscle relaxant. The typical adult daily dose of this medication ranges between $0.75 \mathrm{mg}$ and $4 \mathrm{mg}$ (Stahl, 1993). The control participant was only taking $0.12 \mathrm{mg}$ every other day, did not have any psychological disorders, and thus was not excluded.

\section{Decision-making Outcomes}

Results of decision making outcomes based on the four decision-making measures in OCD and control participants are presented in Table 4. This included three objective measures of decision making (IGT, IST and CGT), and one subjective measure (FIS). Next, an examination of a memory measure (CVLT-II) as a proxy for organizational strategies is presented, as seen in

Table 5. Subjective decision-making outcomes are then reported, followed by an examination of the three objective measures of decision making in relation to the self-report FIS, as seen in Table 6. Finally, the findings associated with self-report measures of ambiguity and impulsivity are examined in relation to decision-making performance.

Objective decision-making tasks. A mixed ANOVA was conducted on the IGT to examine ambiguous decision making and learning over time between groups, with group (OCD, healthy controls) as the between-subjects factor and blocks ( 5 blocks) as the within-subjects 


\section{DECISION MAKING IN OCD}

factor. Results revealed that on the IGT, there was a significant block effect, $F(4,168)=5.35, p$ $<.001, \eta_{\mathrm{p}}^{2}=.113$, indicating that both groups showed learning over time. However, no effect of group was found, $F(4,168)=0.40, p=.808$. An independent samples $t$-test was conducted to examine differences between groups on the IGT Net outcome, which is defined by the number of cards selected from the advantageous decks $(\mathrm{C}+\mathrm{D})$ minus the number of cards of disadvantageous decks $(\mathrm{A}+\mathrm{B})$. No significant differences between groups on IGT Net were found, $t(42)=-1.05, p=.301$.

For the remaining two objective measures of decision making (IST and CGT), data for six and five participants with OCD, respectively, and two controls, were unusable due to technical errors. A mixed ANOVA was conducted on the IST measuring impulsivity and decision making with the outcome measuring the mean number of boxes opened per trial with group (OCD, healthy controls) as the between-subjects factor and condition (cost, no cost) as the within-subjects factor. Results revealed no significant differences between groups on the mean number of boxes opened, $F(1,34)=0.41, p=.525$. Similar models were also conducted on the outcomes measuring total sampling errors and total number of correct answers. There were also no differences found between groups on sampling errors, $F(1,34)=1.21, p=.280$, or correct answers, $F(1,34)=1.17, p=.287$.

Independent samples $t$-tests were conducted to compare the two groups on the dependent outcomes associated with the CGT as a measure of risky decision making. No significant differences emerged between groups on outcomes related to the probability of rational decisions, $t(35)=-0.46, p=.652$, deliberation time, $t(35)=-1.18, p=.247$, the probability of quality decisions, $t(35)=-0.55, p=.586$, or the probability of risk taking behaviour, $t(35)=-0.88, p=$ 


\section{DECISION MAKING IN OCD}

384. Overall, no significant differences emerged between groups on any of the dependent variables for the IGT, IST, and CGT.

Table 4

Mean Decision-making Performance Between Groups

\begin{tabular}{|c|c|c|c|c|c|}
\hline Measure & $\begin{array}{l}\mathrm{OCD} \\
\mathrm{M}(\mathrm{SD})\end{array}$ & $\begin{array}{l}\text { Control } \\
\mathrm{M}(\mathrm{SD})\end{array}$ & Statistic & $p$ & $\begin{array}{l}\text { Effect } \\
\text { Size }\end{array}$ \\
\hline FIS & $50.50(9.10)$ & $35.91(9.79)$ & $t(42)=-5.12$ & $<.001 * * *$ & $r=.62$ \\
\hline IGT Net (CD-AB) & $21.77(25.20)$ & $13.77(25.44)$ & $t(42)=-1.10$ & .301 & $r=.17$ \\
\hline $\begin{array}{l}\text { CGT } p \text { of Rational } \\
\text { Decisions }\end{array}$ & $.53(0.13)$ & $.51(0.14)$ & $t(35)=-.46$ & .652 & $r=.08$ \\
\hline $\begin{array}{l}\text { CGT Deliberation } \\
\text { time }(\mathrm{s})\end{array}$ & $\begin{array}{l}2343.00 \\
(805.00)\end{array}$ & $\begin{array}{l}2021.00 \\
(850.00)\end{array}$ & $t(35)=-1.18$ & .247 & $r=.20$ \\
\hline $\begin{array}{l}\text { CGT } p \text { of Quality } \\
\text { Decisions }\end{array}$ & $.90(0.16)$ & $.87(.21)$ & $t(35)=-.55$ & .586 & $r=.09$ \\
\hline CGT $p$ of Risk Taking & $.57(.12)$ & $.53(.16)$ & $t(35)=-.88$ & .384 & $r=.15$ \\
\hline $\begin{array}{l}\text { IST M Boxes Opened } \\
\text { per Trial (1) }\end{array}$ & $16.84(6.59)$ & $15.66(6.62)$ & $F(1,34)=.02$ & .883 & $\eta^{2}=.001$ \\
\hline $\begin{array}{l}\text { IST M Boxes Opened } \\
\text { per Trial (2) }\end{array}$ & $12.56(5.73)$ & $11.17(6.40)$ & & & \\
\hline IST Errors (1) & $0.88(1.15)$ & $0.75(0.97)$ & $F(1,34)=1.21$ & .280 & $\eta^{2}=.034$ \\
\hline IST Errors (2) & $1.44(1.15)$ & $1.75(1.25)$ & & & \\
\hline $\begin{array}{l}\text { IST Total Trials } \\
\text { Correct (1) }\end{array}$ & $8.88(1.26)$ & $9.15(1.09)$ & $F(1,34)=1.17$ & .287 & $\eta^{2}=.033$ \\
\hline $\begin{array}{l}\text { IST Total Trials } \\
\text { Correct (2) }\end{array}$ & $8.25(1.18)$ & $8.10(1.29)$ & & & \\
\hline
\end{tabular}

Note. $P=$ Probability; $\mathrm{M}=$ Mean; $\mathrm{SD}=$ Standard Deviation; $\mathrm{s}=$ Seconds; IGT = Iowa Gambling Task; CGT $=$ Cambridge Gambling Task; IST $=$ Information Sampling Task; $1=$ no cost condition; $2=$ cost condition; FIS $=$ Frost Indecisiveness Scale. $* * * p<.001$. Due to technical difficulties, $n=20$ for the control group and $n=17$ for the OCD group on the CGT; $n=20$ for the control group and $n=16$ for the OCD group on the and IST.

Organizational strategies as measured by a verbal memory task. Results on the verbal memory measure (CVLT-II), as a representation of organizational strategies in OCD and 


\section{DECISION MAKING IN OCD}

control participants, are presented in Table 5. Independent samples $t$-test were conducted to examine both semantic and serial clustering, which are two outcome variables on the CVLT-II used to measure learning and organizational strategies. For semantic clustering, Levene's test, $F(1,42)=7.33, p=.010$, was significant, indicating that the assumption of homogeneity of variances was not met. Therefore, an analysis that did not assume homogeneity of variance was adopted. Examination of semantic learning revealed that there were no differences in the use of semantic clustering strategies between participants with OCD and controls, $t(37.50)=1.49, p=$ .146. In contrast, results revealed that participants with $\mathrm{OCD}(\mathrm{M}=0.95, \mathrm{SD}=1.46)$ used serial clustering strategies significantly more than control participants $(\mathrm{M}=0.13, \mathrm{SD}=0.87), t(42)=$ 2.26, $p=.029$. Further analyses, using independent samples $t$-tests, examined interference on the CVLT-II. Results revealed that after the presentation of a second word list, participants with OCD $(\mathrm{M}=-17.65, \mathrm{SD}=21.25)$ remembered significantly less words from the first list than controls $(\mathrm{M}=-7.08, \mathrm{SD}=12.16), t(42)=2.02, p=.049$.

Table 5

Mean Performance on Memory Task Between Groups

\begin{tabular}{llllll}
\hline Outcome on CVLT-II & OCD $(n=22)$ & Control $(n=22)$ & & \multicolumn{2}{c}{ Effect } \\
S $(\mathrm{SD})$ & $\mathrm{M}(\mathrm{SD})$ & Statistic & $p$ & Size $(r)$ \\
\hline Semantic Clustering & $1.97(2.22)$ & $3.21(3.19)$ & $t(37.50)=1.49$ & .146 & .24 \\
Serial Clustering & $0.95(1.46)$ & $0.13(0.87)$ & $t(42)=-2.26$ & $.029 *$ & .33 \\
Interference & $-17.65(21.25)$ & $-7.08(12.16)$ & $t(42)=2.02$ & $.049 *$ & .30 \\
\hline
\end{tabular}

Note. $\mathrm{M}=$ Mean; SD = Standard deviation; CVLT-II = California Verbal Learning Test;

Levene's test was significant $(p<.05)$ for Semantic Clustering, thus equal variances were not assumed; $* p<.05$

In summary, participants with OCD were significantly more likely to apply serial strategies to remembering the word list than controls; however, there did not appear to be a 


\section{DECISION MAKING IN OCD}

significant difference between groups for semantic clustering. In addition, participants with OCD showed greater interference than controls when a second word list was presented.

Subjective decision making. To examine subjective decision making between groups, an independent samples $t$-test was conducted using the self-report FIS. Despite the lack of differences between groups on objective measures, the self-report measure revealed statistically significant differences between groups, $t(42)=-5.12, p<.001$, with a large effect, $r=.62$. Participants with OCD $(M=50.50, \mathrm{SD}=9.10)$ reported greater levels of subjective difficulty with decision making than controls $(\mathrm{M}=35.91, \mathrm{SD}=9.79)$. Scores on both the BAI $(r=.65)$ and BDI-II $(r=.64)$ were significantly correlated with FIS scores $(p<.001)$; therefore, to see if diagnostic status would maintain significance even if depression and anxiety were controlled for, a hierarchical linear regression was conducted. Given the significant differences between groups, ethnicity was also included in the model to see if diagnostic group status could explain the model above and beyond these factors. As ethnicity is a demographic characteristic, it was entered into the model first. The second level consisted of clinical symptoms, including depression and anxiety. The third level of the model was the variable of interest, diagnostic group status. Results revealed that ethnicity did not account for any significant variance in self-reported indecision, $F(1,40)=1.87, p=.179$. Although symptoms of anxiety and depression accounted for $45 \%$ of the variance in the model, $R^{2}=.45$, adding group status significantly improved the fit of the model, $F(4,37)=10.36, p<.001$. Incorporating group status into the model accounted for $53 \%$ of the variance in self-reported indecision, $R^{2}=.53$, which is an increase of $8 \%$ from depression and anxiety alone. Thus, it appears that neither ethnicity, anxiety nor depression, had an impact on whether individuals with OCD reported greater perceived difficulty with decision making than controls. 


\section{DECISION MAKING IN OCD}

Relationship between objective and subjective decision making. Pearson's correlation coefficients were computed to examine the relationship between decision-making measures. See Table 6 for a summary. Results revealed no statistically significant associations between objective decision-making outcomes on the IGT, IST and CGT, and self-reported indecision.

Moderator analyses were conducted to further examine the relationship between decisionmaking measures. Self-reported indecision, and objective decision making (as measured by IGT Net) were the variables of interest, with diagnostic group status proposed as a moderator. The analyses showed that diagnostic group status significantly moderated the relationship between IGT Net and FIS, $F(3,39)=11.83, p=.001, R=.69 . \beta=.22, t(1,39)=1.99, p=.040$. Specifically, introducing diagnostic group status into the model demonstrated that as selfreported indecisiveness increased, performance on the IGT improved in those with OCD $(r=.45$, $p=.034)$. The relationship between FIS and IGT scores was nonsignificant for controls $(r=-.17$, $p=.438)$. Overall, results indicate poor convergent validity between objective and subjective measures of decision making, as participants with OCD reported perceived difficulties with decision making, despite the lack of findings to indicate impairments in objective decision making.

\section{Relationship between self-reported intolerance of uncertainty and decision-making}

performance. Pearson's correlation coefficients were computed and independent samples $t$-tests were conducted in order to examine the association between OCD, intolerance of uncertainty (IUS), and decision making. For intolerance of uncertainty scores, Levene's test, $F(1,41)=4.96$, $p=.032$, was significant, indicating that the assumption of homogeneity of variances was not met. Therefore, an analysis that did not assume homogeneity of variance was adopted, which revealed a significant group effect of intolerance of uncertainty, $t(36.75)=-2.78, p=.009$. 


\section{DECISION MAKING IN OCD}

Participants with OCD $(\mathrm{M}=74.52, \mathrm{SD}=15.51)$ reported greater intolerance of uncertainty than controls $(\mathrm{M}=57.86, \mathrm{SD}=23.26)$.

Further to this, results revealed that self-reported indecisiveness was significantly correlated with intolerance of uncertainty, $r=.62, p=.001$, with approximately $39 \%$ of the variance accounted for $\left(r^{2}=.39\right)$. As previous research suggested that intolerance of uncertainty may underlie difficulties with decision making, this was examined using linear regression. Intolerance of uncertainty scores significantly predicted perceived difficulty with decision making, $b=.616, t(42)=5.01, p<.001$. Intolerance of uncertainty also explained $38 \%$ of the variance in self-reported indecision scores, $R^{2}=.38, F(1,41)=25.11, p<.001$. This indicated that as intolerance of uncertainty scores increased by 1 standard deviation, self-reported indecision also increased by 0.616 of a standard deviation. There were no significant associations between intolerance of uncertainty and objective measures of decision making. In summary, results indicated that intolerance of uncertainty is likely related to perceived difficulties with decision making reported in those with OCD.

\section{Self-reported impulsivity related to decision-making performance. Pearson's}

correlation coefficients were computed and independent samples $t$-tests were conducted in order to examine the association between OCD, self-reported impulsivity (BIS-II), and decision making. Self-reported impulsivity was significantly greater in participants with OCD $(\mathrm{M}=$ $64.86, \mathrm{SD}=13.61)$ than in controls $(\mathrm{M}=57.36, \mathrm{SD}=10.11), t(41)=-2.06, p=.046$. The BIS-II was broken down into components of impulsivity based on subscales of the measure, which also resulted in significant differences between groups. Individuals with OCD reported greater nonplanning impulsivity $(\mathrm{M}=25.91, \mathrm{SD}=5.86)$ than controls $(\mathrm{M}=21.32, \mathrm{SD}=4.69), t(41)=-$ 2.84, $p=.007$. Greater attentional impulsivity in those with $\mathrm{OCD}(\mathrm{M}=18.62, \mathrm{SD}=4.40)$ as 


\section{DECISION MAKING IN OCD}

compared to controls $(\mathrm{M}=15.59, \mathrm{SD}=5.97)$ approached significance, $t(41)=-1.89, p=.066$.

There were no differences between groups on the third factor related to motor impulsivity, $t(41)=$ $0.09, p=.931$.

Self-reported impulsivity was also examined in relation to self-reported indecision.

Results revealed that self-reported indecisiveness was significantly correlated with impulsivity, $r$ $=.35, p=.022$, with approximately $12 \%$ of the variance accounted for $\left(r^{2}=.12\right)$. As previous research suggested that a lack of premeditation (nonplanning impulsivity), and a lack of perseverance (attentional-impulsivity) is related to decision-making, this was examined using linear regression. Nonplanning impulsivity significantly predicted perceived difficulty with decision making, $b=.352, t(41)=2.41, p=.020$. Nonplanning impulsivity also explained $12 \%$ of the variance in self-reported indecision scores, $R^{2}=.12, F(1,41)=5.82, p=.020$. Results also revealed that attentional impulsivity significantly predicted perceived difficulty with decision making, $b=.447, t(41)=3.20, p=.003$. Nonplanning impulsivity also explained $20 \%$ of the variance in self-reported indecision scores, $R^{2}=.20, F(1,41)=10.22, p=.003$.

The objective decision-making measures showed a significant moderate association between performance on the IGT and self-reported impulsivity $r=.318, p=.038$. Upon further examination, results revealed that attentional impulsivity was moderately associated with IGT performance, $r=.386, p=.011$, but nonplanning impulsivity was not, $r=.206, p=.186$. No associations were found between total impulsivity scores, subscales of impulsivity, and the variables on the CGT or the IST. Overall, there appeared to be a relationship between selfreported impulsivity and decision making, specifically as measured by the IGT. Despite the fact that the IST is a decision-making task that examines impulsivity, no relationship between selfreported impulsivity and the IST was noted. 


\section{DECISION MAKING IN OCD}

Table 6.

Correlations (r) Among Decision-Making Measures

\begin{tabular}{|c|c|c|c|c|c|c|c|c|c|c|c|}
\hline Measure & FIS & $\begin{array}{l}\text { IGT } \\
\text { Net }\end{array}$ & $\begin{array}{l}\text { CGT } p \text { of } \\
\text { Rational } \\
\text { Decisions }\end{array}$ & $\begin{array}{l}\text { CGT Del- } \\
\text { iberation } \\
\text { time }(\mathrm{s})\end{array}$ & $\begin{array}{l}\text { CGT } p \text { of } \\
\text { Quality } \\
\text { Decisions }\end{array}$ & $\begin{array}{l}\text { CGT } p \\
\text { of Risk } \\
\text { Taking }\end{array}$ & $\begin{array}{l}\text { IST M } \\
\text { Boxes } \\
\text { Opened } \\
(1)\end{array}$ & $\begin{array}{l}\text { IST M } \\
\text { Boxes } \\
\text { Opened } \\
(2)\end{array}$ & $\begin{array}{l}\text { IST } \\
\text { Samplin } \\
\text { g Errors } \\
(1)\end{array}$ & $\begin{array}{l}\text { IST } \\
\text { Sampling } \\
\text { Errors (2) }\end{array}$ & $\begin{array}{l}\text { IST Total } \\
\text { Trials } \\
\text { Correct } \\
\text { (1) }\end{array}$ \\
\hline IGT Net & .20 & $\mathrm{x}$ & & & & & & & & & \\
\hline $\begin{array}{l}\text { CGT } p \text { of Rational } \\
\text { Decisions }\end{array}$ & -.02 & -.05 & $\mathrm{x}$ & & & & & & & & \\
\hline $\begin{array}{l}\text { CGT Deliberation } \\
\text { time }(s)\end{array}$ & -.09 & -.05 & .04 & $\mathrm{x}$ & & & & & & & \\
\hline $\begin{array}{l}\text { CGT } p \text { of Quality } \\
\text { Decisions }\end{array}$ & -.10 & -.01 & .22 & -.18 & $\mathrm{X}$ & & & & & & \\
\hline $\begin{array}{l}\text { CGT } p \text { of Risk } \\
\text { Taking }\end{array}$ & .03 & -.02 & $.97 * *$ & .02 & $.33 *$ & $\mathrm{x}$ & & & & & \\
\hline $\begin{array}{l}\text { IST M Boxes } \\
\text { Opened (1) }\end{array}$ & .24 & -.06 & -.27 & -.11 & -.04 & -.17 & $\mathrm{x}$ & & & & \\
\hline $\begin{array}{l}\text { IST M Boxes } \\
\text { Opened (2) }\end{array}$ & .28 & .03 & $-.53 * * *$ & -.10 & -15 & $-.43 * *$ & $.77 * * *$ & $\mathrm{x}$ & & & \\
\hline $\begin{array}{l}\text { IST Sampling } \\
\text { Errors (1) }\end{array}$ & -.16 & .17 & .19 & .12 & .10 & .13 & $-.81 * * *$ & $-.50 * *$ & $\mathrm{x}$ & & \\
\hline $\begin{array}{l}\text { IST Sampling } \\
\text { Errors (2) }\end{array}$ & -.29 & -.22 & $.43 * *$ & .03 & .26 & $.32^{\wedge}$ & $-.63 * * *$ & $-.83 * * *$ & $.44 * *$ & $\mathrm{x}$ & \\
\hline $\begin{array}{l}\text { IST Total Trials } \\
\text { Correct (1) }\end{array}$ & .08 & -.14 & -.12 & -.07 & -.05 & -.07 & $.75 * * *$ & $.44 * *$ & $-.95 * * *$ & $-.44 * *$ & $\mathrm{x}$ \\
\hline $\begin{array}{l}\text { IST Total Trials } \\
\text { Correct (2) }\end{array}$ & .23 & .22 & $-.36^{*}$ & .03 & -.20 & -.25 & $.71 * * *$ & $.82 * * *$ & $-.53 * * *$ & $-.94 * * *$ & $.52 * * *$ \\
\hline
\end{tabular}




\section{DECISION-MAKING IN OCD}

\section{Other Neuropsychological Measures}

A summary of other neuropsychological measures used in the study to examine motor speed, cognitive speed, response inhibition and cognitive inhibition are presented in Table 7. All of these outcomes were examined using independent samples $t$-tests.

Results revealed no statistically significant differences between OCD and control participants on both psychomotor speed, as measured by Finger Tapping, for the dominant hand, $t(42)=1.55, p=.128$, and nondominant hand, $t(42)=1.84, p=.072$. Similarly, there were no differences between groups for cognitive information processing speed, as measured by the Digit Symbol Test, $t(42)=1.31, p=.199$. This indicated that participants with OCD are not slower than controls when processing information.

In terms of response inhibition, no significant differences in performance on the StopSignal Paradigm, $t(42)=-0.27, p=.789$, as measured by SSRT, were found between groups. Furthermore, an examination of cognitive inhibition, using the Stroop Color-Word Interference Test, indicated no significant differences between OCD and control participants on the word trial, $t(42)=1.40, p=.168$, colour trial, $t(42)=-0.06, p=.955$, or the interference trial, $t(42)=-$ $0.07, p=.944$. These results indicated that participants with OCD did not demonstrate difficulty with motor or cognitive inhibition as compared to controls. 


\section{DECISION-MAKING IN OCD}

Table 7:

Other Neuropsychological Measures

\begin{tabular}{|c|c|c|c|c|c|}
\hline Outcome & $\begin{array}{l}\mathrm{OCD}(n=22) \\
\mathrm{M}(\mathrm{SD})\end{array}$ & $\begin{array}{l}\text { Control }(n=22) \\
\mathrm{M}(\mathrm{SD})\end{array}$ & Statistic & $p$ & $\begin{array}{l}\text { Effect } \\
\text { Size }(r) \\
\end{array}$ \\
\hline \multicolumn{6}{|l|}{ Finger Tapping Test } \\
\hline Dominant Hand & $40.31(8.66)$ & $43.94(6.70)$ & $t(42)=1.55$ & .128 & .23 \\
\hline Nondominant Hand & $37.06(6.78)$ & $40.88(6.99)$ & $t(42)=1.84$ & .072 & .27 \\
\hline \multicolumn{6}{|l|}{ Digit Symbol } \\
\hline \# of Symbols & $70.00(19.73)$ & $78.83(20.09)$ & $t(42)=1.31$ & .199 & .20 \\
\hline \multicolumn{6}{|l|}{ Stop-Signal Paradigm } \\
\hline SSRT & $329.00(108.40)$ & $318.69(129.40)$ & $t(38)=-0.27$ & .789 & .04 \\
\hline \multicolumn{6}{|c|}{ Stroop Color-Word Interference Test } \\
\hline Word & $45.79(9.35)$ & $50.21(11.44)$ & $t(42)=1.40$ & .168 & .21 \\
\hline Colour & $44.49(8.28)$ & $44.35(8.16)$ & $t(42)=-0.057$ & .955 & .01 \\
\hline Word/colour interference & $49.73(10.44)$ & $49.50(10.86)$ & $t(42)=-0.071$ & .944 & .01 \\
\hline
\end{tabular}

Note. $\mathrm{M}=$ Mean; $\mathrm{SD}=$ Standard deviation; $\mathrm{SSRT}=$ Stop signal reaction time; Due to technical difficulties, $n=18$ for participants with OCD on the Stop-Signal Paradigm. 


\section{DECISION-MAKING IN OCD}

\section{Discussion}

The primary purpose of this study was to examine decision making in individuals with OCD as compared to healthy control participants. A review of the findings suggested that some of the a priori hypotheses were supported by the results. Overall, no significant differences between groups on measures of objective decision making were found (IGT, IST and CGT). Performance on a memory task (CVLT-II) as a proxy for organizational strategies indicated differences between groups on serial clustering strategies and the interference caused by the presentation of a second word list. Furthermore, the results of the self-report measure of decision making (FIS) supported the clinical phenomena of complaints of indecisiveness in OCD. However, the self-report measure showed poor convergent validity with the objective measures. Although the presence of decision making deficits remains inconclusive in this population, this study provided evidence that individuals with OCD have perceived deficits in decision making, which likely has implications related to treatment for OCD patients. It is suggested that rather than targeting decision-making ability, treatment should focus on the beliefs and perceptions about one's decision-making ability. Alternatively, it is possible that the objective measures of decision making are not capturing the deficits, as these measures may be tapping a different construct than that related to the subjective measure.

Hypothesis 1 stated that participants with OCD would demonstrate impairments on the IGT as compared to controls. This hypothesis was not supported by the findings of the current study. An analysis across blocks, and a comparison between groups on the Net outcome, indicated that all participants made comparable decisions on the task. Both groups learned to choose cards from the advantageous decks (C and D) and to avoid the disadvantageous decks (A and B) across blocks. These results are supported by some previous research that found no 


\section{DECISION-MAKING IN OCD}

differences in IGT performance between individuals with OCD and controls (Dittrich et al., 2011; Lawrence et al., 2006; Nielen et al., 2002), but are inconsistent with other published studies (Cavallaro et al., 2003; Cavedini et al., 2002; Da Rocha et al., 2011; Long et al., 2012; Starcke et al., 2010; Starcke et al., 2010).

Previous research has demonstrated differences in neuronal activity in the orbitofrontal cortex in OCD patients as compared to healthy controls (Ping et al., 2013; Stern et al., 2013; Whiteside et al., 2004). The orbitofrontal cortex has been indicated as important during the context of decision making. For example, impairment on the IGT has been suggested as indicative of abnormal orbitofrontal cortex functioning (Cavedini et al., 2002). Although there appears to be a relationship between difficulties with decision making and OCD, not all studies have consistently found deficits on decision-making measures. Therefore, future neuroimaging studies are warranted to better decipher the neuropsychological functioning of decision making in OCD, and the extent of involvement of the orbitofrontal cortex.

One possible reason for the inconsistent findings using the IGT may be explained by the measure. It is possible that the ecological validity of the IGT is problematic due to the poor reliability and construct validity that has been reported for the measure (Brand et al., 2005; Brand et al., 2007; Buelow \& Suhr, 2009). Most studies used the IGT as a measure of ambiguous decision making; however, it is unclear if the test taps both ambiguous and risky decision making. Thus, contradictory findings may be explained by concerns with the measure that is often used to examine decision making.

The failure of the current study to find a statistically significant difference between OCD and control participants on the IGT may also be due to the older mean age of participants with OCD $(M=37.23, S D=13.53)$, relative to other studies. Specifically, Da Rocha and colleagues 


\section{DECISION-MAKING IN OCD}

(2011) found that participants with OCD with a mean age of 28.40 (SD = 14.12) had significant impairment on the IGT, compared to controls. In contrast, the study by Dittrich and colleagues used older participants with $\mathrm{OCD}(\mathrm{M}=41.80, \mathrm{SD}=12.50 ; 2011)$ and, like the current study, also did not find impairments on the IGT. There is some evidence that performance on the IGT improves with age, until older adulthood (mid-50s to 60s) when performance declines (Beitz, Salthouse, \& Davis, 2014). Therefore, age may be an important factor contributing to the inconsistent findings in the literature.

Another possible explanation for the differences in findings between studies using the IGT may be severity of symptoms. According to the YBOCS, participants with OCD in the current study were considered to have a moderate severity of symptoms as a group. Similarly, in the study by Dittrich and colleagues (2011), mean symptom severity ranged from mild (for those with sexual/religious obsessions) to moderate (for aggressive symptoms), and no significant difference between groups was found. In contrast, participants in the study by Da Rocha and colleagues (2011) had a mean symptom presentation falling in the severe range on the YBOCS, and participants with OCD demonstrated poorer performance than controls. It has been previously reported that OCD patients with more severe symptoms demonstrated poorer performance on the IGT (Nielen et al., 2002). Thus, there is some indication that the level of severity of obsessive-compulsive symptoms is important to consider when examining decisionmaking deficits. As no impairment on this task was found in the current study, it is possible that in more severe cases of OCD, impairment on the IGT would be reported. Thus, future studies should examine symptom severity as a variable of interest in order to better determine whether this factor contributes to performance decrement. 


\section{DECISION-MAKING IN OCD}

Furthermore, inconsistent results may also be due to the clinical heterogeneity of OCD, as previous research has revealed that symptom subtypes (e.g., primary symptoms of contamination/cleaning, symmetry/ordering, obsessions/checking and hoarding) are associated with certain neurocognitive impairments (Leckman et al., 1997; McKay et al., 2004). For example, Lawrence and colleagues (2006) reported impaired performance on the IGT in those with primary hoarding symptoms compared to healthy controls, and compared to patients low on hoarding symptoms (Lawrence et al., 2006). Due to the small sample size of the current study, an analysis comparing decision-making performance between subtypes of OCD was not possible, and thus future studies should attempt to examine subtypes as a possible factor in whether deficits in decision making occur. Overall, given the large inconsistencies in performance on the IGT in the literature, more research is needed to determine if deficits on this task exist.

Hypothesis 2 stated that participants with OCD would demonstrate impairments on the IST (a measure that taps decision making and impulsivity) as compared to controls. This was not supported. Since impulsivity was suggested as an important component of the decision-making process (Bayard et al., 2011; Torregrossa et al., 2008), and previous research found greater perceived impulsivity in those with OCD compared to controls (Gupta et al., 2013; Summerfeldt et al., 2004), impaired performance on the IST was expected. The current study's nonsignificant result was supported by Chamberlain, Fineberg, Blackwell, and colleagues (2007), where after controlling for multiple comparisons, no differences between groups on decision-making outcomes on the IST were reported. However, inconsistent with the current study, these authors also found that performance across conditions differed between OCD and control participants. These authors found that when an incentive to choose a majority colour earlier by revealing fewer boxes before making a decision was introduced in the second condition (cost condition), 


\section{DECISION-MAKING IN OCD}

controls adjusted their behaviour and opened fewer boxes than in the first condition, which was not the case for the OCD group (Chamberlain, Fineberg, Blackwell, et al., 2007). The authors concluded that this result was likely representative of the cognitive rigidity often seen in OCD, and thus may not be indicative of impaired decision making. Given that only two studies (including the current study) have examined decision making in OCD using the IST, future studies are warranted.

Hypothesis 3 stated that participants with OCD would perform similarly to controls on the CGT. This hypothesis was supported. Analyses that compared groups on the four dependent variables (probability of rational decisions, deliberation time, probability of quality decisions, and probability of risk taking behaviour) demonstrated comparable performance between OCD and control participants. Results of the current study were consistent with other studies that examined risky decision making using the CGT, GDT, and high-risk scenarios (Chamberlain, Fineberg, Blackwell, et al., 2007; Chamberlain, Fineberg, Menzies, et al., 2007; Foa et al., 2003; Long et al., 2012; Starcke et al., 2009; Starcke et al., 2010; Watkins et al., 2005), which suggested intact decision-making performance in OCD during risky decision making. However, Dittrich and colleagues (2011) reported impairment on rational risky decision making for those with symmetry/ordering and sexual/religious symptoms as compared to other symptom subtypes. Given that the current study did not examine subtypes of OCD, it is possible that different symptom presentations between the samples contributed to the inconsistent findings. Overall, previous literature appeared to largely support the findings that individuals with OCD did not demonstrate impairments on tasks of risky decision making. It has been suggested that organizational strategies are important in the context of decision making, as individuals are required to evaluate alternatives during this process (Olley et al., 2007). Despite this, there are no 


\section{DECISION-MAKING IN OCD}

current decision-making measures that tap organizational strategies. Although the IGT claims to require the use of organizational strategies on the task (Bechara et al., 1994), there are no dependent outcome variables to assess this component of decision making. As previous research has found that organizational strategies mediate performance on certain memory measures (Savage et al., 2000), the CVLT-II was employed to examine this component of decision making.

Hypothesis 4 stated that strategic learning on the CVLT-II would be impaired in those with OCD. This hypothesis was partially supported by the results, as there were differences between groups on outcome variables that directly tapped organizational strategies. The two variables examined included serial clustering (attempting to remember the words in the order they were presented), and semantic clustering (attempting to group words by categories in order to facilitate memory). In the current study, participants with OCD were more likely to use serial clustering strategies than controls, as demonstrated by a medium effect size $(r=.33)$. No significant differences between OCD and control participants were found on the use of semantic clustering strategies; however, an examination of the means found that participants with OCD used semantic strategies less than controls. The effect size for semantic clustering was close to the effect seen in serial clustering $(r=.24)$, but was not large enough to bring about significant differences. Thus, it is possible that the current study was under powered to detect differences in semantic clustering between groups. Previous research has found that participants with OCD implemented semantic clustering strategies less than controls (Tukel et al., 2012), and it is possible that this would have been found in the current study with a larger sample size. Given that serial clustering is not as beneficial as semantic clustering in improving performance (Delis et al., 2000), it is interesting that participants with OCD demonstrated a greater use of this 


\section{DECISION-MAKING IN OCD}

strategy than controls. Since serial clustering strategy is not a primary outcome on the CVLT-II, future research should aim to report this finding in the results. Interestingly, participants with OCD experienced significantly more interference than controls when remembering the first list of words after the presentation of the second list of words, which may be related to executive functioning. This result supported previous research that suggested deficits in executive functioning in OCD patients (Olley et al., 2007; Tukel et al., 2012). Overall, these findings suggested that organizational strategies involved in verbal learning may be important factors to consider in future research.

It should be noted that the current study examined strategic learning using a verbal memory measure. The Rey-Osterrieth Complex Figure Test (RCFT; Meyers \& Meyers, 1995) tests visuospatial memory, which asks participants to copy and recall a complex figure. The RCFT also taps organizational strategies in the context of strategic learning by examining the manner in which participants copy the figure, as well as subsequent performance on memory outcomes. Savage and colleagues (2000) reported that organizational strategies also mediated performance on nonverbal memory tasks in OCD. In addition, it was reported that greater organizational strategies during the copy condition resulted in improved performance on the RCFT. Thus, future research comparing verbal and nonverbal organizational strategies in OCD would likely add to the limited literature on strategy in decision making.

Hypothesis 5, which stated that self-reported decision making as measured by the FIS would be poorer in those with OCD compared to controls, was supported. This result remained significant even after considering the variance accounted for by ethnicity, anxiety, and depression. This result makes theoretical sense, given that indecisiveness is often reported as an issue in those with OCD (Steketee \& Frost, 2003). Findings from the current study add to the 


\section{DECISION-MAKING IN OCD}

limited literature on subjective reports of decision making in OCD patients. Taken together, the findings indicated that perception of decision-making ability may be impaired in OCD, rather than having actual deficits in decision making on objective measures. Alternatively, it may be that we are not measuring the same construct or process as that being captured by the self-report measure.

A functional Magnetic Resonance Imaging study by Stern and colleagues (2013) indicated that individuals with OCD only demonstrated impairments in decision making as compared to controls when there was no uncertainty inherent in the task. When uncertainty was present as part of the measure, participants with OCD performed similarly to controls. The authors concluded that greater activation in the limbic and paralimbic brain regions (important for emotion and behaviour) during decision making may have exacerbated the subjective experience of uncertainty and indecision in OCD, even when there was no uncertainty inherent in the task. These authors concluded that targeting the perception of decision-making difficulties and associated anxiety during decision making should be a focus of treatment, rather than focusing on "how to" make decisions. Given the lack of objective deficits in decision making and the self-reported difficulties with decision making, the findings of the current study supported this previous research.

Hypothesis 6, which stated that subjective and objective decision-making performance would be related, was partially supported. Correlational analyses computed between the various decision-making measures demonstrated that there was very little relationship between these measures. In fact, the only significant correlations between measures were the probability of rational decisions on the CGT, and three of the dependent variables on the cost condition of the IST: mean number of boxes opened, sampling errors, and total trials correct. This suggested that 


\section{DECISION-MAKING IN OCD}

although all of the measures are supposed to be assessing decision making, they are likely tapping different components of this complex construct.

To further examine the association among decision-making measures, whether group status was a significant moderator of the relationship between the IGT and FIS, was examined. Within the OCD group, performance on the IGT increased as subjective indecision increased, which was contrary to expectations. For controls, there was no significant relationship between scores on the IGT and FIS. A possible reason for these results was based on the perception of difficulty with decision making that is examined in the self-report measure (i.e., how decisionmaking performance was perceived by the patient may not be related to actual decision-making ability). Again, this finding further supported the idea that the maladaptive beliefs about decision-making ability should be the target in OCD treatment, rather than providing specific decision-making strategies.

Another explanation for the unexpected relationship between the FIS and IGT may be due to the fact that objective and subjective tests tap different constructs. The self-report FIS inquired about the process of decision making (e.g., "I do not get assignments done on time because I cannot decide what to do first," "It seems that deciding on the most trivial thing takes me a long time"), and anxiety associated with decision making (e.g., "I become anxious when making a decision," "I often worry about making the wrong choice"). The FIS also attempted to capture what the decision-making process was like in real-life settings (e.g., "When ordering from a menu, I usually find it difficult to decide what to get," "I have a hard time planning my free time"). These questions were in contrast to the behavioural neuropsychological measures of decision making that largely rely on gambling-like scenarios, as in the IGT, IST, and CGT. Although tests like the IGT purport to mimic real-life decision making (Bechara et al., 1994), it 


\section{DECISION-MAKING IN OCD}

is possible that these objective measures may not evaluate the construct in this manner as well as previously thought.

Overall, results on the IGT, CGT and IST suggested intact decision making in OCD patients. The findings from the current study also demonstrated that participants with OCD, as a group, had differences in organizational strategies during the memory task. A perceived difficulty with decision making was present in the OCD sample, suggesting poor convergent validity between objective and subjective tests.

Decision making is a complex neuropsychological process that involves many components and can be affected by many factors. Thus, a task designed to incorporate various components of decision making, or more studies examining measures that tap different components, are needed. Further to this, future research that highlights the process of making decisions, rather than outcomes (Raynard et al., 1997), is warranted. In addition, perhaps the development of objective measures of decision making with greater ecological validity would provide better insight into this process in OCD.

Hypothesis 7 stated that there would be a relationship between decision-making outcomes and intolerance of uncertainty in OCD. This hypothesis was supported. Intolerance of uncertainty is a negative reaction to uncertain or unforeseen circumstances or events (Dugas \& Koerner, 2005). Evidence has suggested intolerance of uncertainty as a maintaining factor contributing to various anxiety and depressive disorders, including GAD, OCD, social anxiety disorder, panic disorder, agoraphobia, and depression (McEvoy, \& Mahoney, 2011; 2012). In the current study, participants with OCD reported greater intolerance of uncertainty than controls, which was consistent with previous research (Gentes \& Ruscio, 2011; Fergus \& Wu, 2010). 


\section{DECISION-MAKING IN OCD}

In the current study, intolerance of uncertainty predicted perceived difficulty with decision making, indicating that it is possible that this transdiagnostic construct of anxiety may be related to the subjective indecision in OCD; however, intolerance of uncertainty was not related to objective decision-making performance. The results of previous research on uncertainty in decision making (Stern et al., 2013), and the findings that perceived decisionmaking ability was poor in OCD, have important treatment implications for OCD patients. As mentioned, it can be suggested that maladaptive beliefs about one's ability to make decisions and tolerating uncertainty should be a focus in the treatment of OCD, rather than an explicit focus on decision making. One of the primary targets in cognitive-behavioural therapy (CBT) is to understand unrealistic thoughts, and appraisals of those thoughts, that contribute to symptoms of anxiety and associated dysfunctional emotions (Clark, 2004). This is done by first identifying the maladaptive beliefs and cognitive processes (Clark, 2004). Patients are taught, through goaloriented therapy, that these thoughts and the associated anxiety are not harmful and can be tolerated. Behavioural techniques such as exposure and response prevention (ERP) have been shown to be highly effective in the treatment of OCD (Clark, 2004). ERP is designed to focus on avoidance (as compulsive acts are often used to reduce anxiety from associated obsessions) by exposing patients to their fears. A combination of both cognitive and behavioural techniques is often used in the treatment of OCD, and tailoring these strategies to the cognitive biases unique to the patient may be important. Thus, if a patient endorses high intolerance of uncertainty and perceived difficulties with decision making, CBT strategies may be useful in targeting these problems.

Hypothesis 7 further stated that there would be a relationship between decision-making outcomes and impulsivity, and this was also supported. Although there were no differences 


\section{DECISION-MAKING IN OCD}

between groups on the IST, participants with OCD reported greater perceived impulsivity than controls on the self-report BIS-II, which supported previous research (Gupta et al., 2013; Summerfeldt et al., 2004). Consistent with the study by Gupta and colleagues (2013), the results of the current study revealed that participants with OCD reported higher nonplanning impulsivity compared to controls, which indicated poorer planning and less enjoyment on difficult tasks (Patton et al., 1995). There was also a trend toward higher attention-impulsiveness (involved in making quick decisions), but no differences in motor impulsiveness (involved in engaging in behaviours without thinking). Scores on both the nonplanning and attentional impulsivity subscales of the BIS-II predicted scores of self-reported indecision on the FIS, which suggested that severity of certain components of impulsivity may be related to perceived difficulties with decision making.

In the current study, as overall self-reported impulsivity increased, performance on the IGT improved, which was contrary to expectations. In addition, the results showed that the attentional facet of impulsivity was most related to performance on the IGT, an effect that was of moderate size and statistically significant. As scores on attentional impulsivity increased, so did performance on the IGT. However, no associations between nonplanning or motor impulsivity and IGT performance were found. Previous studies found that those with high impulsivity, or high scores on the nonplanning subscale, had poorer performance on the IGT than controls, and those with low impulsivity, or low nonplanning scores, had better performance (Franken et al., 2008; Zermatten et al., 2005). One possible reason for the inconsistent results is that previous research used healthy nonclinical samples while the current study used OCD patients.

However, the observed positive relation between impulsivity and decision-making performance was in line with an earlier study conducted by Franken and Muris (2005). This 


\section{DECISION-MAKING IN OCD}

study found no association between decision-making performance on the IGT and dysfunctional impulsivity, but the researchers indicated that a higher level of a reward sensitivity trait associated with impulsivity resulted in improved performance on the IGT. Therefore, the association between high impulsivity and poorer decision-making performance did not appear to be consistent across studies, given the findings of a positive association between impulsivity and IGT performance, and the lack of association between impulsivity and other decision-making measures.

A possible reason for the inconsistent results is the differences in the measures used. For example, Franken and colleagues (2008) used one of the computerized versions of the IGT that progressively increased the cost of punishment, whereas the current study used the card version where the cost of punishment did not increase. In addition, multiple self-report questionnaires were used to assess impulsivity. For example, on the Impulsiveness Scale used by Franken and colleagues (2008), scores were rated on a dichotomous yes/no scale that focused on behavioural control and delay in gratification. Zermatten and colleagues (2005) used the French version of the Impulsive Behavior Scale, which measured items on a 4-point Likert scale, similarly to the BIS-II. It is possible that different versions of the questionnaire resulted in differences in the findings between studies, and thus more research in the area of impulsivity and decision making is needed.

The inclusion of multiple measures of impulsivity in future studies appears warranted in order to determine if different approaches to measuring the construct relate to performance on various decision-making tasks. In addition, differentiating between different subtypes of OCD to further understand the relationship between impulsivity and symptoms of OCD is important (Zermatten et al., 2008), and future research should also investigate this. 


\section{DECISION-MAKING IN OCD}

An examination of other neuropsychological measures was included in the current study in order to rule out confounding variables and other possible explanations of the findings. It was found that participants with OCD and control participants did not differ on level of premorbid functioning as measured by a proxy for intelligence, which indicated that the findings of the study were not related to intelligence, as measured by reading ability. In addition, participants with OCD in the current sample were not slower than controls during tasks, as indicated by similar performance between groups on measures of psychomotor and cognitive information processing speed. Finally, findings indicated that performance between OCD and control participants did not differ on measures of motor or cognitive inhibition, and thus it is not likely that these factors influenced the results.

This study contributed to the limited literature on decision making in OCD, which is currently fraught with inconsistent results. This study employed a large battery of tests composed of clinical and neurocognitive measures to assess for comorbidities, severity of clinical symptoms, and cognitive impairment. This was the first study to evaluate decision making in OCD using multiple measures that assessed proposed components of the construct, including ambiguity, impulsivity, perception of risk, and organizational strategies. It was also presumed to be the first study to compare subjective and objective decision making in OCD, using a multimodal method of assessment (i.e., tests and questionnaires), and to measure decision making using three objective measures. Further to this, all participants had a principal diagnosis of OCD, and those for whom criteria were not met (i.e., those with hoarding disorder only) were excluded from the sample. It is also unlikely that depression contributed to the results of the current study as: 1) only patients with mild or moderate depressive severity were included in the study; 2) where high correlations between cognitive performance and depression were found, a 


\section{DECISION-MAKING IN OCD}

hierarchical Regression was performed to control for these symptoms; and 3) no correlations were found between depressive scores and other significant differences in cognitive functioning.

The results of the current study suggested two possible explanations for the findings: 1 ) the need to target beliefs about decision-making ability, rather than actual deficits, or 2) the need to develop a measure of decision making that objectively captures the process of decision making, as we may not be currently tapping the construct in the manner that we thought. This finding has implications for the treatment of individuals with OCD, as a better understanding of decision-making difficulties unique to a patient could provide diagnostic information to add to the case conceptualization of that patient.

Despite its many strengths, the current study was not without limitations. First, due to technical difficulties, data from participants in both the OCD and control groups were lost on the IST, CGT and Stop-Signal Paradigm, and thus results on these measures were analyzed with a sample size that was smaller than that estimated for power a priori. Given the small sample size, it is possible that there was not adequate power to detect differences in cognitive performance. Thus, the results should be interpreted with caution, and findings should be replicated with a larger sample size. Some other potentially confounding variables, such as medication, were not controlled for in this study due to the small sample size. Since the clinical participants were largely recruited from an outpatient hospital setting, varying levels of medication status were present in the sample. Furthermore, ethnicity was significantly different between groups, with a higher proportion of individuals identifying as Caucasian in the OCD sample and a higher proportion of individuals identifying as Asian in the control sample. However, this difference did not appear to affect the results on decision-making tasks, as shown by the significant differences between groups on subjective decision making, even after ethnicity was controlled for. Future 


\section{DECISION-MAKING IN OCD}

research should attempt to match participants on ethnicity to ascertain if these variables impact the results.

The majority of clinical participants had comorbid mood and anxiety disorders, which is common is OCD; however, given the small sample size, we were unable to compare performance across these groups. As the study was not adequately powered to analyze differences between subtypes of OCD, future research should also compare performance on decision-making measures across theoretically supported subtypes. Studies with clinical control groups (e.g., primary depression, other anxiety disorders) and subtypes of OCD may help elucidate differences in decision making between these clinical presentations.

Despite the large number of statistical analyses performed, a Bonferroni correction for multiple comparisons was not used. As the statistical tests completed were designed to examine neuropsychological performance based on a-priori hypotheses, each measure was viewed as a separate analysis for statistical purposes, and $p<.05$ was reported.

\section{Conclusion}

The purpose of the current study was to examine the neurocognitive process of decision making in individuals with OCD, using multiple measures. The presence of decision-making deficits in this population remained inconclusive, due to poor convergent validity between objective and subjective measures of decision making. Nevertheless, this study provided support that individuals with OCD have perceived deficits in decision making, which has implications related to treatment in this population. Furthermore, differences in the application of organizational strategies on a memory measure were reported, but more research in this area is warranted. Intolerance of uncertainty and impulsivity may be related to perceived difficulties with decision making in OCD, but more research examining these constructs is also needed. The 


\section{DECISION-MAKING IN OCD}

results of this study have added to the limited literature on neurocognition and decision making in OCD, and multiple suggestions for future research were discussed. 


\section{DECISION-MAKING IN OCD}

\section{References}

Abramowitz, J. S., \& Deacon, B. J. (2006). Psychometric properties and construct validity of the Obsessive-Compulsive Inventory- Revised: Replication and extension with a clinical sample. Journal of Anxiety Disorders, 20, 1016-1035.

doi:10.1016/j.janxdis.2006.03.001

American Psychiatric Association (2013). Diagnostic and statistical manual of mental disorders, $5^{\text {th }} e d$. Washington, DC: Author.

Bayard, S., Raffard, S., \& Gely-Nargeot, M. (2011). Do facets of self-reported impulsivity predict decision-making under ambiguity and risk? Evidence from a community sample. Psychiatry Research, 190, 322-326. doi:10.1016/j.psychres.2011.06.013

Bechara, A., Damasio, A. R., Damasio, H., \& Anderson, S. W. (1994). Insensitivity to future consequences following damage to human prefrontal cortex. Cognition, 50, 7-15. doi: 10.1016/0010-0277(94)90018-3

Beck, A.T., Epstein, N., Brown, G., \& Steer, R.A. (1988). An inventory for measuring clinical anxiety: Psychometric properties. Journal of Consulting and Clinical Psychology, 56, 893-897. doi: 10.1037/0022-006X.56.6.893

Beck, A. T., \& Steer, R.A. (1993). Beck Anxiety Inventory: Manual. San Antonio, TX: Pearson Assessment.

Beck, A. T., Steer, R. A., \& Brown, G. K. (1996). Beck Depression-II: Manual. San Antonio, TX: Pearson Assessment.

Beitz, K. M., Salthouse, T. A., \& Davis, H. P. (2014). Performance on the Iowa Gambling Task: From 5 to 89 years of age. Journal of Experimental Psychology: General, 143, 16771689. doi: $10.1037 / \mathrm{a} 0035823$ 


\section{DECISION-MAKING IN OCD}

Billieux, J., Gay, P., Rochat, L., \& Van der Linden, M. (2010). The role of urgency and its underlying psychological mechanisms in problematic behaviours. Behaviour Research and Therapy, 48, 1085-1096. doi:10.1016/j.brat.2010.07.008

Brand, M., Fujiwara, E., Borsutzky, S., Kalbe, E., Kessler, J., \& Markowitsch, H.J. (2005). Decision-making deficits of Korsakoff patients in a new gambling task with explicit rules-associations with executive functions. Neuropsychology, 19, 267-277. doi: 10.1037/0894-4105.19.3.267

Brand, M., Recknor, E. C., Grabenhorst, F., \& Bechara, A. (2007). Decisions under ambiguity and decisions under risk: Correlations with executive functions and comparisons of two different gambling tasks with implicit and explicit rules. Journal of Clinical and Experimental Neuropsychology, 29, 86-99. doi: 10.1080/13803390500507196

Buelow, M., \& Suhr, J. (2009). Construct validity of the Iowa Gambling Task. Neuropsychology Review, 19, 102-114. doi: 10.1007/s11065-009-9083-4

Buhr, K., \& Dugas, M.J. (2002). The Intolerance of Uncertainty Scale: Psychometric properties of the English version. Behaviour Research and Therapy, 40, 931-94. doi: 10.1016/S0005-7967(01)00092-4

Burdick, K. E., Robinson, D G. Malhotra, A. K., \& Szeszko, P. R. (2008). Neurocognitive profile analysis in obsessive-compulsive disorder. Journal of the International Neuropsychological Society, 14, 640-645. doi: 10.1017/S1355617708080727

Cambridge Cognition Ltd. (2006). Cambridge Neuropsychological Test Automated Battery (CANTAB). Author: Cambridge: UK.

Cavallaro, R., Cavedini, P., Mistretta, P., Bassi, T., Angelone, S. M., Ubbiali, A., \& Bellodi, L. (2003). Basal-corticofrontal circuits in schizophrenia and obsessive-compulsive 


\section{DECISION-MAKING IN OCD}

disorder: A controlled, double dissociation study. Society of Biological Psychiatry, 54, 437-443. doi:10.1016/S0002-3223(03)01814-0

Cavedini, P., Gorini, A., \& Bellodi, L. (2006). Understanding OCD: Focus on decision-making. Neuropsychology Review, 16, 3-15. doi: 10.1007/s11065-006-9001-y

Cavedini, P., Riboldi, G., D'Annucci, A., Belotti, P., Cisima, M., \& Bellodi, L. (2002). Decisionmaking heterogeneity in obsessive-compulsive disorder: Ventromedial prefrontal cortex function predicts different treatment outcomes. Neuropsychologia, 40, 205-211. doi: 10.1016/S0028-3932(01)00077-X

Chamberlain, S, R., Fineberg, N. A., Blackwell, A. D., Clark, L., Robbins, T. W. \& Sahakian, B. J. (2007). A neuropsychological comparison of obsessive-compulsive disorder and trichotillomania. Neuropsychologia, 45, 654-662. doi:

10.1016/j.neuropsychologia.2006.07.016

Chamberlain, S. R., Fineberg, N. A., Menzies, L. A., Blackwell, A. D., Bullmore, E. T., Robbins, T. W. \& Sahakian, B. J. (2007). Impaired cognitive flexibility and motor inhibition in unaffected first-degree relatives of patients with obsessive-compulsive disorder. American Journal of Psychiatry, 164, 335-338. doi: 10.1176/appi.ajp.164.2.335

Clark, D. A. (2004). Cognitive-Behavioral Therapy for OCD. New York, NY: Guilford Press.

Clark, L., Bechara, A., Damasio, H., Aitken, M. R. F., Sahakian, B. J. \& Robbins, T. W. (2008). Differential effects of insular and ventrome-dial prefrontal cortex lesions on risky decision-making. Brain, 131, 1311-1322. doi: 10.1093/brain/awn066

Clark, L., Robbins, T. W., Ersche, K. D., \& Sahakian, B. J. (2006). Reflection impulsivity in current and former substance users. Biological Psychiatry, 60, 515-522. doi: 10.1016/j.biopsych.2005.11.007 


\section{DECISION-MAKING IN OCD}

Da Rocha, F., Alvarenga, N., Malloy-Diniz, L., \& Correa, H. (2011). Decision-making impairment in OCD as measured by the Iowa Gambling Task. Arquivos de NeuroPsiquiatria, 69, 642-647. doi: 10.1590/S0004-282X2011000500013

Delis, D.C., Kramer, J.H., Kaplan, E., \& Ober, B.A. (2000). California Verbal Learning Test: Second Edition. San Antonio, TX: Pearson Assessment.

Dettore, D. \& O'Connor, K. (2013). OCD and cognitive illusions. Cognitive Therapy and Research, 37, 109-121. doi: 10.1007/s10608-012-9440-0

Dittrich, W. H., \& Johansen, T. (2013). Cognitive deficits of executive functions and decisionmaking in obsessive-compulsive disorder. Scandinavian Journal of Psychology, 54, 393-400. doi: 10.1111/sjop.12066

Dittrich, W. H., Johansen, T., Landrø, N. I. \& Fineberg, N. A. (2011). Cognitive performance and specific deficits in OCD symptom dimensions: III. Decision-making and impairments in risky choices. German Journal of Psychiatry, 14,13-25.

Dugas, M. J., \& Koerner, N. (2005). Cognitive-behavioral treatment for generalized anxiety disorder: Current status and future directions. Journal of Cognitive Psychotherapy, 19, 61-81. doi: 10.1891/jcop.19.1.61.66326

Fadda, E., Sottocorno, S., Martoni, R., Galimberti, E., \& Bellodi, L. (2011). No evidence for deficient set-shifting in obsessive-compulsive disorder. European Psychiatry, 26, 153. doi: 10.1016/S0924-9338(11)71864-8

Fergus, T. A., \& Wu, K. D. (2010). Do symptoms of generalized anxiety and obsessivecompulsive disorder share cognitive processes? Cognitive Therapy and Research, 34, 168-176. doi: 10.1007/s10608-009-9239-9 


\section{DECISION-MAKING IN OCD}

First, M., Spitzer, R., Gibbon, M., Williams, J. (1997). Structured Clinical Interview for DSMIV, Research Version. Washington, DC: American Psychiatric Press.

Foa, E. B., Huppert, J., D., Leiberg, S., Langner, R., Kichic, R., Hajcak, G.,... Salkovskis, P.M. (2002). The obsessive-compulsive inventory: Development and validation of a short version. Psychological Assessment, 14, 485-496. doi: 10.1037/1040-3590.14.4.485

Foa, E. B., Mathews, A., Abramowitz, J. S., Amir, N., Przeworski, A., Riggs, D. S.,...Alley, A. (2003). Do patients with obsessive-compulsive disorder have deficits in decisionmaking? Cognitive Therapy and Research, 27, 431-445. doi:

10.1023/A:1025424530644

Fogel, J. (2003). An epidemiological perspective of OCD in children and adolescents. Canadian Child Adolescent Psychiatry Review, 12, 33-36.

Franken, I. H. A., \& Muris, P. (2005). Individual differences in decision-making. Personality and Individual Differences, 39, 159-253. doi: 10.1016/j.paid.2005.04.004

Franken , I. H. A., van Strien, J. W., Nijs, I., \& Muris, P. (2008). Impulsivity is associated with behavioral decision-making deficits. Psychiatry Research, 158, 155-163. doi: 10.1016/j.psychres.2007.06.002

Frost, R. O., \& Shows, D. L. (1993). The nature and measurement of compulsive indecisiveness. Behaviour Research and Therapy, 31, 683-692. doi: 10.1016/0005-7967(93)90121-A

Gentes, E. L., \& Ruscio, A. M. (2011). A meta-analysis of the relation of intolerance of uncertainty to symptoms of generalized anxiety disorder, major depressive disorder, and obsessive-compulsive disorder. Clinical Psychology Review, 31, 923-933. doi:10.1016/j.cpr.2011.05.001 


\section{DECISION-MAKING IN OCD}

Golden, C. J. (1976). Identification of brain disorders by the Stroop Color and Word Test. Journal of Clinical Psychology, 32, 654-658.

Goodman, W. K., Price, L. H., \& Rasmussen, S. A. (1989). The Yale-Brown Obsessive Compulsive Scale. I. Development, use and reliability. Archives of General Psychiatry, 46, 1006-1011. doi:10.1001/archpsyc.1989.01810110048007

Gupta, S. K., Khess, C. R. J., \& Venkatesan, S. (2013). Subjective perception of impulsivity in patients with obsessive-compulsive disorder. Journal of the Indian Academy of Applied Psychology, 39, 228-236.

Heaton, R. K., Grant, I., \& Matthews, C. G. (1992). Comprehensive norms for an expanded Halstead-Reitan battery. Lutz, FL: Psychological Assessment Resources.

Holdnack, H.A. (2001). Wechsler Test of Adult Reading: WTAR. San Antonio, TX: Pearson Assessment.

Lawrence, N. S., Wooderson, D., Mataix-Cols, R., David, A., Speckens, M. L., \& Phillips, M. L. (2006). Decision making and set shifting impairments are associated with distinct symptom dimensions in OCD. Neuropsychology, 20, 409-419. doi: 10.1037/08944105.20.4.409

Leckman, J., Grice, D. E., Boardman, J., Zhang, H., Vitale, A., Bondi, C.,..Pauls, D. L. (1997). Symptoms of obsessive-compulsive disorder. American Journal of Psychiatry, 154, 911-917.

Logan, G. D., Cowan, W. B., \& Davis, K. A. (1984). On the ability to inhibit simple and choice reaction time responses: A model and a method. Journal of Experimental Psychology: Human Perception and Performance, 10, 276-291. doi: 10.1037/0096-1523.10.2.276 


\section{DECISION-MAKING IN OCD}

Long, Z., Kai, W., Yi-Fu, J., Chun-Yan, Z., Ping, Y., \& Hui-Juan, M. (2012). Dissociation of decision making under ambiguity and decision making under risk in patients with obsessive-compulsive disorder. Chinese Mental Health Journal, 26, 209-214.

Markarian, Y., Larson, M. J., Aldea, M. A., Baldwin, S. A., Good, D., Berkeljon, A.,..McKay, D. (2010). Multiple pathways to functional impairment in obsessive-compulsive disorder. Clinical Psychology Review, 30, 78-88. doi: 10.1016/j.cpr.2009.09.005

McEvoy, P. M., \& Mahoney, A. E. J. (2012). To be sure, to be sure: Intolerance of uncertainty mediates symptoms of various anxiety disorders and depression. Behavior Therapy, 43, 533-545. doi: 10.1016/j.beth.2011.02.007

McEvoy, P. M., \& Mahoney, A. E. J. (2011). Achieving certainty about the structure of intolerance of uncertainty in a treatment-seeking sample with anxiety and depression. Journal of Anxiety Disorders, 25, 112-122. doi:10.1016/j.janxdis.2010.08.010

McKay, D., Abramowitz, J. S., Calamari, J. E., Kyrios, M., Radomsky, A., Sookman, D.,...Wilhelm, S. (2004). A critical evaluation of obsessive-compulsive disorder subtypes: Symptoms versus mechanisms. Clinical Psychology Review, 24, 283-313. doi: 10.1016/j.cpr.2004.04.003

Menzies, L., Chamberlain, S. R., Laird, A. R., Thelen, S. M., Sahakian, B. J., \& Bullmore, E. T. (2008). Integrating evidence from neuroimaging and neuropsychological studies of obsessive-compulsive disorder: The orbitofronto-striatal model revisited. Neuroscience and Biobehavioural Reviews, 32, 525-549. doi: 10.1016/j.neubiorev.2007.09.005

Meyers, J. E., \& Meyers, K. R. (1995). Rey Complex Figure Test under four different administration procedures. The Clinical Neuropsychologist, 9, 63-67. doi:10.1080/13854049508402059 


\section{DECISION-MAKING IN OCD}

Nielen, M. M. A., Veltman, D. J., de Jong, R., Mulder, G., \& den Boer, J. A. (2002). Decisionmaking performance in obsessive compulsive disorder. Journal of Affective Disorders, 69, 257-260. doi: 10.1016/S0165-0327(00)00381-5

Obsessive-Compulsive Cognitions Working Group (2003). Psychometric validation of the obsessive beliefs questionnaire and the interpretation of intrusions inventory: Part I. Behaviour Research and Therapy, 41, 863-878. doi: 10.1016/S0005-7967(02)00099-2

Oglesby, M. E., Medley, A. N., Norr, A. M., Capron, D. W., Korte, K. J., \& Schmidt, N. B. (2013). Intolerance of uncertainty as a vulnerability factor for hoarding behaviors. Journal of Affective Disorders, 145, 227-231. doi: 10.1016/j.jad.2012.08.003

Olley, A., Malhi, G., \& Sachdev, P. (2007). Memory and executive functioning in OCD: A selected review. Journal of Affective Disorders, 104, 15-23. doi:

10.1016/j.jad.2007.02.023

Overman, W., Graham, L., Redmond, A., Eubank, R., Boettcher, L., Samplawski, O., \& Walsh, K. (2006). Contemplation of moral dilemmas eliminates sex differences on the Iowa Gambling Task. Behavioral Neuroscience, 120, 817-825. doi: 10.1037/07357044.120.4.817

Patton, J.H., Stanford, M. S., \& Barratt, E. S. (1995). Factor structure of the Barratt Impulsiveness Scale. Journal of Clinical Psychology, 51, 768-774.

Ping, L., Su-Fang, L., Hai-Ying, H., Zhang-Ye, D., Jia, L., Zhi-Hua, G.,... \& Zhan-Jiang, L. (2013). Abnormal spontaneous neural activity in obsessive-compulsive disorder: A resting-state functional magnetic resonance imaging study. Plos one, 8. doi: 10.1371/journal.pone.0067262 


\section{DECISION-MAKING IN OCD}

Rao, N. P., Reddy, Y. C. J., Kumar, K. J., Kandavel, T., \& Chandrashekar, C. R. (2008). Are neuropsychological deficits trait markers in OCD? Progress in NeuroPsychopharmacology and Biological Psychiatry, 32, 1574-1579. doi: 10.1016/j.pnpbp.2008.05.026

Raynard, R., Crozier, W. R., \& Svenson, O. (1997). Decision-making: Cognitive models and explanations. London, UK: Routledge.

Rogers, R. D., Owen, A. M., Middleton, H. C., Williams, E. J., Pickard, J. D.,... Sahakian, B. J. (1999). Choosing between small, likely rewards and large, unlikely rewards activates inferior and orbital prefrontal cortex. Journal of Neuroscience, 19, 9029-9038.

Saleem, T., Gul, S., \& Khalily, M. T. (2012). Quality of life of individuals having OCD with and without comorbid psychiatric disorders. Pakistan Journal of Psychology, 43.

Savage, C. R., Deckersbach, T., Wilhelm, S. L., Rauch, S. L., Baer, L., Reid, T., \& Jenike, M. A. (2000). Strategic processing and episodic memory impairment in obsessive-compulsive disorder. Neuropsychology, 14, 141-151. doi: 10.1037//0894-4105.14.1.141

Schneibel, R., Brakemeier, E., Wilbertz, G., Dykierek, P., Zobel, I., \& Schramm, E. (2012). Sensitivity to detect change and the correlation of clinical factors with the Hamilton Depression Rating Scale and the Beck Depression Inventory in depressed inpatients. Psychiatry Research, 198, 62-67. doi: 10.1016/j.psychres.2011.11.014

Shin , N. Y., Lee, T. Y., Kim, E., \& Kwon, J. S. (2014). Cognitive functioning in obsessivecompulsive disorder: A meta-analysis. Psychological Medicine, 44, 1121-1130. doi:10.1017/S0033291713001803 


\section{DECISION-MAKING IN OCD}

Sorensen, C. B., Kirkeby, L., \& Thomsen, P. H. (2004). Quality of life with OCD: A selfreported survey among members of the Danish OCD Association. Nordic Journal of Psychiatry, 58, 231-236. doi: 10.1080/08039480410006287

Stahl, S. (1993). Alprazolam-XR: Dosage considerations. Psychiatric Annals, 27-31.

Stanford, M. S., Mathias, C. W., Dougherty, D. M., Lake, S. L., Anderson, N. E., \& Patton, J. H. (2009). Fifty years of the Barratt Impulsiveness Scale: An update and review. Personality and Individual Differences, 47, 385-395. doi: 10.1016/j.paid.2009.04.008

Starcke, K., Tuschen-Caffier, B., Markowitsch, H. J., \& Brand, M. (2010). Dissociation of decisions in ambiguous and risky situations in obsessive-compulsive disorder. Psychiatry Research, 175, 114-120. doi:10.1016/j.psychres.2008.10.022

Starcke, K., Tuschen-Caffier, B., Markowitsch, H. J., \& Brand, M. (2009). Skin conductance responses during decisions in ambiguous and risky situations in obsessive-compulsive disorder. Cognitive Neuropsychiatry, 14, 199-216. doi: 10.1080/13546800902996831

Stein, M.B., Forde, D.R., Anderson, G., \& Walker, J.R. (1997). Obsessive-compulsive disorder in the community: An epidemiologic survey with clinical reappraisal. American Journal of Psychiatry, 154, 1120-1126.

Steketee, G., \& Frost, R. (2003). Compulsive hoarding; Current status of the research. Clinical Psychology Review, 23, 905-927. doi:10.1016/j.cpr.2003.08.002

Stern, E. R., Welsh, R. C., Gonzalez, R., Fitzgerald, K. D., Abelson, J. L., \& Taylor, S. F. (2013) Subjective uncertainty and limbic hyperactivation in obsessive-compulsive disorder. Human Brain Mapping, 34, 1956-1970. doi: 10.1002/hbm.22038

Stevanovic, D. (2011). Quality of Life Enjoyment and Satisfaction Questionnaire- short form for quality of life assessments in clinical practice: A Psychometric study. Journal of 


\section{DECISION-MAKING IN OCD}

Psychiatric and Mental Health Nursing, 18, 744-750. doi: 10.1111/j.13652850.2011.01735.x

Summerfeldt, L. J., Hood, K., Antony, M. M., Richter, M. A., \& Swinson, R. P. (2004). Impulsivity in obsessive-compulsive disorder: Comparisons with other anxiety disorders and within tic-related subgroups. Personality and Individual Differences, 36, 539-553. doi:10.1016/S0191-8869(03)00113-2

Thobaben, M. (2012). Obsessive-compulsive disorder (OCD): Symptoms and interventions. Home Health Care Management and Practice, 24, 211-213. doi:

$10.1177 / 1084822312441364$

Tolin, D. F., Abramowitz, J. S., Brigidi, B. D., \& Foa, E. B. (2003). Intolerance of uncertainty in obsessive-compulsive disorder. Journal of Anxiety Disorders, 17, 233-242. doi: 10.1016/S0887-6185(02)00182-2

Tolin, D. F., Kiehl, K. A., Worhunsky, P., Book, G.A., \& Maltby, N. (2008). An exploratory study of the neural mechanisms of decision-making in compulsive hoarding. Psychological Medicine, 39, 325-336. doi:10.1017/S0033291708003371

Torregrossa, M. M., Quinn, J. J., \& Taylor, J. R. (2008). Impulsivity, compulsivity, and habit: The role of orbitofrontal cortex revisited. Society of Biological Psychiatry, 63, 253-255. doi:10.1016/j.biopsych.2007.11.014

Tukel, R., Gurvit, H., Ertekin, B. A., Oflaz, S., Ertekin, E., Baran, B.,...Atalay, F. (2012). Neuropsychological functioning in obsessive-compulsive disorder. Comprehensive Psychiatry, 53, 167-175. doi: 10.1016/j.comppsych.2011.03.007

Vandenbroucke, C.L., \& Gabriëls, L. (2012). The decision-making process in obsessivecompulsive disorder. Tijdschrift voor Psychiatrie, 54, 39-49. 


\section{DECISION-MAKING IN OCD}

Watkins, L. H., Sahakian, B. J., Robertson, M. M., Veale, D.M., Rogers, R. D., Pickard, K. M.,...Robbins, T. W. (2004). Executive function in Tourette's syndrome and obsessivecompulsive disorder. Psychological Medicine, 35, 571-582. doi:

10.1017/S0033291704003691

Wechsler, D. (1997). Wechsler Adult Intelligence Scale, $3^{\text {rd }}$ ed. (WAIS-III). San Antonio, TX: Pearson Assessment.

Whiteside, S. P., Port, J. D., \& Abramowitz, J. S. (2004). A meta-analysis of functional neuroimaging in obsessive-compulsive disorder. Psychiatry Research: Neuroimaging, 132, 69-79. doi:10.1016/j.pscychresns.2004.07.001

Woody, S. R., Steketee, G., \& Chambless, D. L. (1995). Reliability and validity of the YaleBrown Obsessive-Compulsive Scale. Behavior Research and Therapy, 33, 597-605. doi: 10.1016/0005-7967(94)00076-V

World Health Organization (2001). Mental health: A call for action by World Health Ministers. Ministerial Round Tales, 54th World Health Assembly. Retrieved from http://www.who.int/mental_health/advocacy/en/Call_for_Action_MoH_Intro.pdf

Zermatten, A., \& Van der Linden, M. (2008). Impulsivity in non-clinical persons with obsessivecompulsive symptoms. Personality and Individual Differences, 44, 1824-1830. doi:10.1016/j.paid.2008.01.025

Zermatten, A., Van der Linden, M., d'Acremont, M., Jermann, F., \& Bechara, A. (2005). Impulsivity and decision-making. Journal of Nervous and Mental Disease, 193, 647-650. doi: 10.1097/01.nmd.0000180777.41295.65 